\title{
Cooperative Multi-Agent Control of Heterogeneous Storage Devices Distributed in a DC Microgrid
}

\author{
Thomas Morstyn, Student Member, IEEE, Branislav Hredzak, Senior Member, IEEE, and Vassilios G. \\ Agelidis, Senior Member, IEEE
}

\begin{abstract}
This paper proposes a multi-agent control strategy to coordinate power sharing between heterogeneous energy storage devices distributed throughout a DC microgrid. Without requiring a central controller, the proposed control strategy extends the benefits offered by hybrid energy storage systems to DC microgrids with batteries and ultracapacitors spatially distributed at different levels of the power distribution hierarchy. The proposed control strategy has the following advantages. 1) The high frequency microgrid load is provided by the ultracapacitors. 2) The low frequency load is provided by batteries used for bulk energy storage during islanded mode, and the main grid during grid connected operation. 3) The ultracapacitor voltages are regulated at a desired reference. 4) State of charge balancing is provided between the batteries. 5) The energy storage systems cooperate based on neighbor-to-neighbor output feedback over a sparse communication network. The only communication requirement is a spanning tree from the ultracapacitor leaders and battery leaders to their respective followers. Simulations are presented demonstrating the performance of the proposed control strategy for a 380 VDC datacenter during grid connected and islanded operation.
\end{abstract}

Index Terms-Batteries, DC microgrid, distributed cooperative control, hybrid energy storage, leader tracking synchronization, ultracapacitors.

\section{INTRODUCTION}

$\mathbf{E}$ NERGY storage devices can be used to provide a range of power network services including peak shaving, increased power quality and increased network reliability [1]. The adoption of power network energy storage (ES) is being driven by rapid technological development, the increased adoption of intermittent renewable generation sources and the need for high reliability and high power quality distribution [2].

These trends have also motivated the development of DC microgrids. A DC microgrid is made up of a low voltage DC distribution network connecting loads, generation sources and storage devices, which can be controlled to operate as part of the main grid or autonomously in islanded mode [3]. Many modern

Manuscript received February 11, 2015; revised June 18, 2015; accepted August 10, 2015. Paper no. TPWRS-00215-2015.

The authors are with the Australian Energy Research Institute and the School of Electrical Engineering and Telecommunications, University of New South Wales (UNSW Australia), Sydney, NSW 2052, Australia (e-mail: t.morstyn@student.unsw.edu.au; b.hredzak@unsw.edu.au; vassilios.agelidis@unsw.edu.au).

Color versions of one or more of the figures in this paper are available online at http://ieeexplore.ieee.org.

Digital Object Identifier 10.1109/TPWRS.2015.2469725 generation sources such as Photovolatic (PV) and variable speed wind, as well as storage devices such as batteries and ultracapacitors, are DC based. A DC distribution system requires fewer AC-DC power stages to connect these sources, reducing power conversion losses [4]. Further, it has been shown that DC microgrids can provide levels of reliability two orders of magnitude above AC microgrids [5]. DC microgrids supported by ES devices have been proposed for applications including PV power plants [6], high power quality distribution [7] and datacenters [8].

DC microgrid ES devices can be broadly divided according to their intended function into power quality regulation ES and bulk ES [2]. Existing ES technologies present a trade-off between energy density and power density as well as other characteristics such as cycle life, efficiency and current ramp rate. Hybrid ES systems incorporate multiple ES technologies so that they can be used for both power quality regulation and bulk ES. In a hybrid ES system the high frequency load should be assigned to a storage technology suitable for power quality regulation such as ultracapacitors, which have high power densities, relatively low cost per $\mathrm{kW}$ and high cycle life [9], [10]. However, ultracapacitors have low energy densities and high cost per $\mathrm{kWh}$. Bulk ES is provided by technologies with high energy densities and low cost per $\mathrm{kWh}$, such as batteries, fuel cells or compressed air [11]. In a hybrid ES system only the low frequency load is assigned to the bulk ES technology, reducing the peak power it must be provisioned for. For batteries, servicing only the low frequency load reduces lifetime deterioration through lower temperature rise, lower cycle rate and reduced depth of discharge [9], [12]. Fuel cells and compressed air storage have limited current ramp rates and thus are only suitable for servicing the low frequency load [13], [14].

It can also be desirable to distribute ES devices throughout a power network, rather than rely on a central ES device. Storage devices collocated with variable loads can balance load spikes, so that a smaller peak load is seen at higher levels in the power distribution hierarchy, reducing operational and capital expenditure [15]. Alternatively, ES may need to be placed in remote locations due to space limitations or security considerations [16]. In [17] it was shown that for datacenters, operational and capital expenditure savings can be obtained with high power density ES technologies located near loads, and bulk ES technologies at higher levels of the power distribution hierarchy. Introducing distributed ES requires an energy balancing control strategy since storage devices that prematurely run out of energy are not able to make use of their power capacities [18]. 
Also, in the case of battery ES, charge discrepancies will cause additional lifetime deterioration due to increased depth of discharge.

A range of control strategies have been proposed for hybrid ES systems [19]. However, these control strategies do not consider coordination between storage devices that are spatially distributed throughout a DC microgrid. Decentralized control strategies have been proposed for power sharing and energy balancing between distributed storage devices in DC microgrids [20]-[22]. However, these control strategies treat the storage devices as homogeneous, distinguished only by their state of charge (SoC) and power rating. Therefore, they are not able to provide for the qualitatively different behavior desired from distributed storage devices based on different technologies.

Centralized control strategies for control of distributed storage devices with different characteristics are proposed in [15], [17], [23], and [24]. However, a centralized control strategy introduces a single point of failure and reduces scalability [25]. These limitations motivate the application of distributed cooperative control. Under a distributed cooperative control strategy the autonomous agents of a multi-agent system pursue common control objectives based only on local information and neighbor-to-neighbor communication over a sparse communication network [26], [27]. Distributed control strategies provide advantages in terms of robustness, extensibility and flexibility over centralized control strategies [28], [29]. The theory of distributed control for leader tracking synchronization in multi-agent systems used in this paper is established in [30]-[34].

Distributed cooperative control strategies have been used for accurate current sharing and secondary voltage control in DC microgrids [35], [36]. Distributed cooperative control for energy balancing between homogeneous ES devices in DC microgrids was presented in [37] and [38]. Coordination between microgrid battery ES systems using power line signaling was presented in [39]. This removes the need for a central controller. However, this control strategy is not fully distributed in the sense that each ES system must communicate with all of the other ES systems. Also, the finite frequency range of power line signaling limits the maximum number of ES systems. None of these papers consider heterogeneous ES technologies which should have qualitatively different operation.

This paper proposes a multi-agent cooperative control strategy to coordinate power sharing between heterogeneous ES devices distributed throughout a DC microgrid. Without requiring a central controller, the proposed control strategy extends the benefits offered by hybrid energy storage systems to DC microgrids with batteries and ultracapacitors spatially distributed at different levels of the power distribution hierarchy. The proposed control strategy has the following advantages. 1) The high frequency load is provided locally by ultracapacitors, making use of their high power density to reduce the load seen at higher levels of the power distribution hierarchy. 2) The low frequency load is provided by the batteries during islanded operation and the main grid during grid connected operation. Therefore, the batteries are only used for bulk energy storage, rather than power quality regulation. 3) The ultracapacitor voltages are maintained around a desired reference and $\mathrm{SoC}$

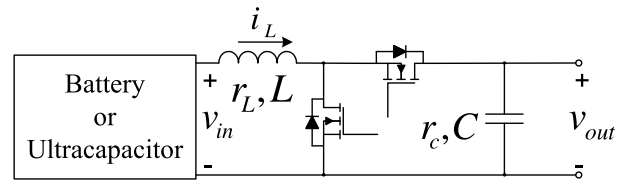

Fig. 1. Bidirectional DC-DC boost converter for interfacing an ultracapacitor or battery to the DC microgrid.

balancing is provided between the batteries. Cooperative control ensures that none of the ES devices will prematurely run out of energy, so their full power capacity remains available. 4) The ES systems use only neighbor-to-neighbor output feedback over a sparse communication network. The only communication requirement is a spanning tree from the ultracapacitor leaders and battery leaders to their respective followers. Simulations are presented demonstrating the performance of the proposed control strategy for a $380 \mathrm{VDC}$ datacenter during grid connected and islanded operation.

This paper is organized as follows. Section II describes the principle of operation of the proposed control strategy. Section III presents the models of the ultracapacitor and battery ES systems used for cooperative control design. Section IV presents the design of the cooperative control including synchronization and stability analysis. Section V presents a simulation case study demonstrating the performance of the proposed control strategy. Section VI concludes the paper.

\section{PRINCIPLE OF OPERATION}

In this study we consider a DC microgrid with a grid connected bidirectional converter, distributed batteries providing bulk ES and ultracapacitors collocated with loads for power quality regulation. Placing high power density ES with loads allows demand spikes to be supplied locally reducing the peak demand that must be supplied by the grid connected converter and batteries [17]. As shown in Fig. 1, the ES devices are connected to the DC microgrid by bidirectional DC-DC boost converters so that their output current can be controlled for charging/discharging.

The proposed control strategy has four primary objectives.

1) The microgrid bus voltage must be regulated to maintain stability and power quality.

2) The high frequency load should be supplied by the ultracapacitors.

3) The ultracapacitor voltages should be maintained around a reference voltage so that they do not run out of energy when feeding large demand spikes.

4) The batteries should maintain a balanced SoC.

The DC microgrid has two modes of operation, grid connected mode and islanded mode. During grid connected mode the grid connected converter should be operated to regulate the $\mathrm{SoC}$ of the batteries. During islanded mode the battery ES systems regulate the voltage of the ultracapacitors, which provide the microgrid load. Since the batteries maintain a balanced SoC, none will prematurely run out of energy, and their full power capacity will be available to maintain the ultracapacitor voltages. Therefore, the microgrid power balance will be maintained until all of the microgrid ES systems are exhausted. If this occurs, 
V-I Droop Control

(included for multi-leader case)

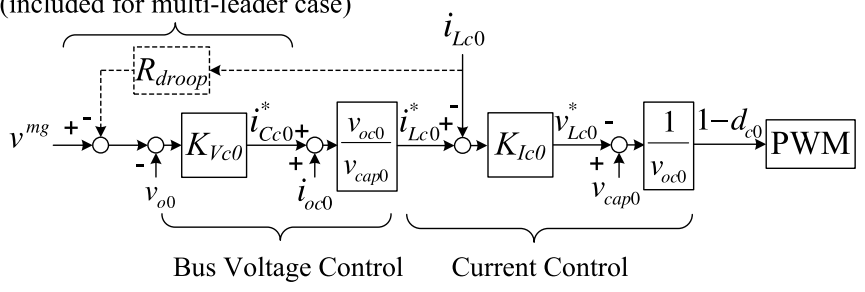

Fig. 2. Ultracapacitor leader local control system.

load shedding will be required. Similarly, in the case of excess supply, such as from renewable generation, curtailment will not be required until all of the ES systems reach their maximum energy level. Strategies for load shedding/generation curtailment are not addressed in this study.

The DC microgrid can be described as a multi-agent system with five types of agents, each operating autonomously with limited communication to achieve the control objectives. These are the ultracapacitor leaders, ultracapacitor followers, battery leaders, battery followers, and the grid connected converter.

\section{A. Ultracapacitor Leader}

A power imbalance will lead to a change in the microgrid bus voltage. If the power balance is not restored, the microgrid voltage will collapse. The ultracapacitor leader is operated to regulate the DC microgrid bus voltage to a reference voltage $v^{m g}$, ensuring that the microgrid power balance is maintained. Ultracapacitors are suited to balancing microgrid power fluctuations due to their high power density and high cycle life. The ultracapacitor leader output current reference is set using the outer loop voltage control strategy from [40]. All of the ES systems use the inner current loop control strategy from [40]. A block diagram of the ultracapacitor leader control system is shown in Fig. 2.

Multiple ultracapacitor leaders can be incorporated into the microgrid to remove a potential single point of failure. In this case, current sharing between the ultracapacitor leaders can be provided by V-I droop control, so that additional communication is not required. The ultracapacitor leaders regulate their local bus voltage to a drooped voltage reference, $v^{*}$, where $v^{*}=v^{m g}-R_{d r o o p} i_{L c 0}$. To prevent the microgrid voltage limits from being violated, the droop gain should be selected as $R_{\text {droop }} \leq\left(\Delta v / i_{L c 0}^{\max }\right)$ where $\Delta v$ is the maximum allowed microgrid bus voltage deviation and $i_{L c 0}^{\max }$ is the maximum ultracapacitor leader inductor current.

\section{B. Ultracapacitor Followers}

It is desirable for load variations to be balanced locally to reduce the peak demand seen at higher levels of the power distribution hierarchy. The high power density and cycle life of ultracapacitors makes them a suitable ES technology for this purpose. Ultracapacitor follower agents are placed at the microgrid load buses to achieve this. A slower cooperative control strategy is implemented between them, to prevent the ultracapacitor voltages from diverging too far from one another. The ultracapacitors inject or absorb additional power based on the

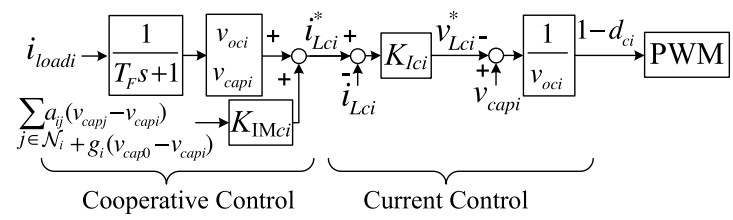

Fig. 3. Ultracapacitor follower local control system.

difference between their voltage and the voltage of their neighbors, so that none will prematurely run out of energy.

The inductor current reference $i_{L c i}^{*}$ of each ultracapacitor follower is set to balance the variable load at its local bus $i_{\text {load } i}$, modified by a local cooperative controller $K_{\mathrm{IM} c i}$. The local bus load is measured by a local current sensor and passed through a first order low pass filter with time constant $T_{F}$. The cooperative controller adjusts the current reference based on the difference between the local ultracapacitor voltage and the voltage of its neighbors, implementing a distributed leader tracking synchronization protocol. The only requirement for the communication network connecting the ultracapacitors is that it must contain a spanning tree with each ultracapacitor leader as a root node. Any imbalance in the ultracapacitor output powers will be reflected in the microgrid bus voltage, and will be balanced by the ultracapacitor leader, so communication from the followers back to the leaders is not required. A block diagram of the local control system used by each ultracapacitor follower is shown in Fig. 3.

\section{Battery Leader}

Battery ES systems are used to provide bulk energy storage. By regulating the ultracapacitor voltage rather than the microgrid bus voltage, the battery ES system current control can be tuned so that the batteries only provide the low frequency microgrid load, without negatively impacting on the DC microgrid power quality.

The battery leader receives the voltage from a neighboring ultracapacitor $v_{\text {cap } j}$. A PI controller sets the battery current reference to regulate the ultracapacitor voltage to a desired reference $v_{\text {cap }}^{*}$. Under the distributed control strategy the remaining ultracapacitors converge to this voltage. The battery leader PI controller for the ultracapacitor voltage control loop is designed to operate on a slower time-scale than the ultracapacitor leader bus voltage controller, so the batteries provide only the low frequency load. A block diagram of the battery leader control system is shown in Fig. 4. Multiple battery leaders can be included in the DC microgrid. SoC balancing between the leaders is provided by augmenting the battery leaders' current control with the cooperative control strategy used by the battery followers. In this case the communication network should provide a spanning tree between the battery leaders.

The most common charging strategy for lithium-ion and lead-acid batteries has two regions of operation, 1) a current-limited region below a maximum voltage, and 2) a constant voltage region at the float voltage [20]. During the current-limited charging region, the battery charging current can be controlled, as long as it is kept below the maximum current limit. Note that depending on the current limit enforced, the battery operates in this region for $70 \%-90 \%$ of its total capacity [41], [42]. Once the float voltage is reached, the battery charge 


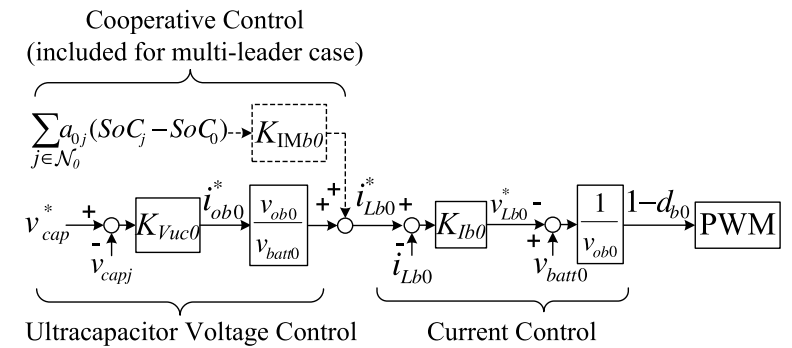

Fig. 4. Battery leader local control system.

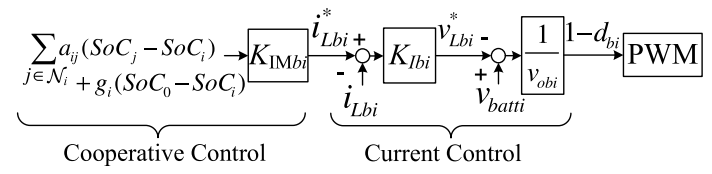

Fig. 5. Battery follower local control system.

acceptance efficiency reduces, and constant voltage charging is preferred to prevent damaging the battery. In the constant voltage charging region the batteries act as loads in the microgrid. Therefore, for the purposes of battery current control in this study, only operation in the current-limited charging region is considered, and the $\mathrm{SoC}$ at which the batteries reach the float voltage is defined as $100 \%$.

\section{Battery Followers}

The battery followers are connected by a second distributed communication network that must provide a spanning tree with the battery leaders as root nodes. The current reference of each battery is set by a local cooperative controller $K_{\mathrm{IM} b i}$ based on the difference between its $\mathrm{SoC}$ and the state charge of its neighbors to implement a distributed leader tracking synchronization protocol. Any imbalance in the battery output powers will be reflected in the ultracapacitor voltage level, and will be balanced by the battery leader. Therefore, the microgrid power balance is maintained while the batteries converge to a common SoC. A block diagram of the local control system used by each battery follower is shown in Fig. 5.

\section{E. Grid Connected Converter}

The microgrid operating mode is set by the real output power of the bidirectional grid connected converter. During islanded mode the low frequency microgrid load is provided by the batteries. In grid connected mode a PI controller sets the converter real power reference to regulate the $\mathrm{SoC}$ of a neighboring battery. Under the distributed control strategy the remaining batteries converge to this SoC. The converter real power reference is achieved based on the d-q axis direct current control strategy from [43]. In this study it is assumed that the $\mathrm{SoC}$ of the batteries should be regulated to $100 \%$ during grid connected operation.

\section{ENERgy Storage System Modeling}

In this section state space models are developed for the ultracapacitor and battery ES systems. These models are used to design the ES system cooperative controllers in Section IV.

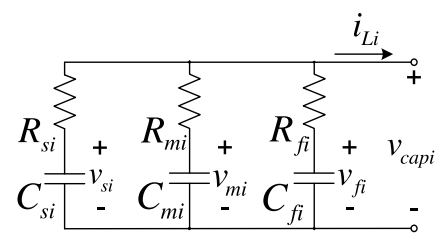

Fig. 6. Ultracapacitor three time constant equivalent circuit model.

\section{A. Ultracapacitor Modeling}

The ultracapacitors are modeled by the three time constant equivalent circuit model from [44] shown in Fig. 6. The $i$ th ultracapacitor's voltage dynamics can be described by the following state space model:

$$
\begin{aligned}
& \dot{x}_{\text {cap } i}=A_{\text {cap } i} x_{\text {cap } i}+B_{\text {cap } i} i_{L c i} \\
& v_{\text {cap } i}=C_{\text {cap } i} x_{\text {cap } i}+D_{\text {cap } i} i_{L c i} \text {, where } \\
& x_{\text {cap } i}=\left[\begin{array}{lll}
v_{f i} & v_{m i} & v_{s i}
\end{array}\right]^{\mathrm{T}} \\
& A_{\text {cap } i}=\left[\begin{array}{ccc}
\frac{R_{x i}-R_{f i}}{C_{f i} R_{f i}^{2}} & \frac{R_{x i}}{C_{f i} R_{f i} R_{m i}} & \frac{R_{x i}}{C_{f i} R_{f i} R_{s i}} \\
\frac{R_{x i}}{C_{m i} R_{m i} R_{f i}} & \frac{R_{x i}-R_{m i}}{C_{m i} R_{m i}^{2}} & \frac{R_{x i}}{C_{m i} R_{m i} R_{s i}} \\
\frac{R_{x i}}{C_{s i} R_{s i} R_{f i}} & \frac{R_{x i}}{C_{s i} R_{s i} R_{m i}} & \frac{R_{x i}-R_{s i}}{C_{s i} R_{s i}^{2}}
\end{array}\right] \\
& B_{\text {cap } i}=\left[\begin{array}{lll}
\frac{-R_{x i}}{C_{f i} R_{f i}} & \frac{-R_{x i}}{C_{m i} R_{m i}} & \frac{-R_{x i}}{C_{s i} R_{s i}}
\end{array}\right]^{\mathrm{T}} \\
& C_{\text {сар } i}=\left[\begin{array}{lll}
\frac{R_{x i}}{R_{f i}} & \frac{R_{x i}}{R_{m i}} & \frac{R_{x i}}{R_{s i}}
\end{array}\right], D_{\text {cap } i}=\left[-R_{x i}\right] \\
& R_{x i}=\left(1 / R_{f i}+1 / R_{m i}+1 / R_{s i}\right)^{-1}
\end{aligned}
$$

where $v_{\text {cap } i}$ is the ultracapacitor voltage and $i_{L c i}$ is the DC-DC converter inductor current.

\section{B. Battery Modeling}

Using the Unnewehr universal battery model and SoC definition from [45] the SoC dynamics and battery voltage of the $i$ th battery ES system are described by

$$
\begin{aligned}
& S \dot{S o} C_{i}=B_{\text {batt } i} i_{L b i}, \text { where } B_{\text {batt } i}=\frac{-\eta_{i}}{C_{n i}} \\
& v_{\text {batt } i}=E_{\text {batt } 0 i}-r_{\text {batt } i} i_{L b i}-K_{\text {batt } i} S o C_{i} .
\end{aligned}
$$

$S o C_{i}$ is the battery SoC, $\eta_{i}$ is the battery Coulombic efficiency, $C_{n i}$ is the nominal battery capacity in ampere-seconds, $v_{\text {batt } i}$ is the battery output voltage, $E_{\mathrm{batt} 0 i}$ is the internal battery voltage, $r_{\text {batt } i}$ is the internal battery resistance, and $K_{\text {batt } i}$ is the polarization constant.

\section{Bidirectional DC-DC Converter Current Loop Modeling}

Each ES system has a bidirectional DC-DC converter controlled with the inner loop current control strategy from [40]. A PI current controller sets the inductor voltage reference $v_{L i}^{*}$ to achieve the desired current reference. The PI current controller is described by the following state equations:

$$
\begin{aligned}
v_{L i}^{*} & =k_{I P i}\left(i_{L i}^{*}-i_{L i}\right)+k_{I I i} \phi_{i} \\
\dot{\phi}_{i} & =i_{L i}^{*}-i_{L i}
\end{aligned}
$$

where $k_{I P i}$ and $k_{I I i}$ are the PI controller proportional and integral gain, $\phi_{i}$ is the PI controller integral state, $i_{L i}^{*}$ is the inductor current reference, and $i_{L i}$ is the inductor current. Feed- 
forward control is used to cancel the variable gain and disturbance caused by variations in the DC-DC converter input voltage (e.g. ultracapacitor/battery voltage) and output voltage (DC bus voltage) [40]. Therefore the DC-DC converter current loop dynamics averaged over its switching period can be modeled by the following state space model:

$$
\begin{aligned}
& \dot{x}_{\mathrm{conv} i}=A_{\text {conv } i} x_{\mathrm{conv} i}+B_{\text {conv } i} i i_{L i}^{*}, \text { where } \\
& x_{\text {conv } i}=\left[\begin{array}{ll}
i_{L i} & \phi_{i}
\end{array}\right]^{\mathrm{T}} \\
& A_{\text {conv } i}=\left[\begin{array}{cc}
\frac{-r_{L i}-k_{I P i}}{L_{i}} & \frac{k_{I I i}}{L_{i}} \\
-1 & 0
\end{array}\right], B_{\text {conv } i}=\left[\begin{array}{ll}
\frac{k_{I P i}}{L_{i}} & 1
\end{array}\right]^{\mathrm{T}} .
\end{aligned}
$$

\section{Combined Energy Storage System State Space Models}

Let the dynamics of the $i$ th ES system follower be generically described by the following state space model $\Sigma_{i}$ :

$$
\Sigma_{i}:\left\{\begin{array}{l}
\dot{x}_{i}=A_{i} x_{i}+B_{i} i_{L i}^{*} \\
y_{i}=C_{i} x_{i}
\end{array}\right.
$$

For the ultracapacitor ES systems (1) and (5) are combined to obtain the output, state vector and system matrices of $\Sigma_{i}$ :

$$
\begin{aligned}
& y_{i}=v_{\text {cap } i}, x_{i}=\left[\begin{array}{lllll}
v_{f i} & v_{m i} & v_{s i} & i_{L c i} & \phi_{i}
\end{array}\right]^{\mathrm{T}} \\
& A_{i}=\left[\begin{array}{ccc}
A_{\text {cap } i} & B_{\text {cap } i} & 0_{3 \times 1} \\
0_{2 \times 3} & A_{\text {conv } i}
\end{array}\right] \\
& B_{i}=\left[\begin{array}{c}
0_{3 \times 1} \\
B_{\text {conv } i}
\end{array}\right], C_{i}=\left[\begin{array}{lll}
C_{\text {cap } i} & D_{\text {cap } i} & 0
\end{array}\right] .
\end{aligned}
$$

For the battery ES systems (2) and (5) are combined to obtain the output, state vector and system matrices of $\Sigma_{i}$ :

$$
\begin{aligned}
& y_{i}=S o C_{i}, x_{i}=\left[\begin{array}{lll}
S o C_{i} & i_{L b i} & \phi_{i}
\end{array}\right]^{\mathrm{T}} \\
& A_{i}=\left[\begin{array}{ccc}
0 & B_{\text {batt } i} & 0 \\
02 \times 1 & A_{\text {conv } i}
\end{array}\right] \\
& B_{i}=\left[\begin{array}{c}
0 \\
B_{\mathrm{conv} i}
\end{array}\right], C_{i}=\left[\begin{array}{lll}
1 & 0 & 0
\end{array}\right] .
\end{aligned}
$$

\section{Cooperative Control Design}

Voltage balancing between the ultracapacitor ES systems and SoC balancing between the battery ES systems can be framed as leader tracking synchronization problems. Let $y_{0}(t)$ be the output trajectory of an ES system leader and $y_{1}(t), \ldots, y_{N}(t)$ be the output trajectory of $N$ ES system followers. Synchronization is achieved if the following conditions are met [34].

1) There are initial conditions such that the follower output trajectories follow the leader trajectory:

$$
y_{1}(t)=\cdots=y_{N}(t)=y_{0}(t), t \geq 0 .
$$

2) For all other initial conditions the follower output trajectories asymptotically approach the leader trajectory:

$$
\lim _{t \rightarrow \infty}\left\|y_{i}(t)-y_{0}(t)\right\|=0, i=1, \ldots, N .
$$

The proposed control strategy is supported by two communication networks, one connecting the ultracapacitor ES systems and a second connecting the battery ES systems. Each communication network can be described by a directed graph $\mathcal{G}(\mathcal{V}, \mathcal{E})$ with nodes $\mathcal{V}=\{0, \ldots, N\}$ and edges $\mathcal{E} \subset \mathcal{V} \times \mathcal{V}$. Node 0 represents the ES system leader, nodes $\{1, \ldots, N\}$ represent the ES system followers, and edges $(i, j) \in \mathcal{E}$ represent the communication links between them. The neighbors of node $i$ are given by $\mathcal{N}_{i}$, where $j \in \mathcal{N}_{i}$ if $(j, i) \in \mathcal{E}$. Direct communication from the leader to its neighboring followers is described by the pinning matrix $\mathbf{G}=\operatorname{diag}\left(g_{i}\right)$, where $g_{i}=1$ if $(0, i) \in \mathcal{E}$ and $g_{i}=0$ otherwise. Communication between the follower nodes is described by the graph adjacency matrix $\mathbf{A}=[a]_{i j} \in \mathbb{R}^{N \times N}$, where $a_{i j}=1$ if $j \in \mathcal{N}_{i}$ and $a_{i j}=0$ otherwise. The graph degree matrix $\mathbf{D}=\operatorname{diag}\left(d_{i}\right)$, where $d_{i}=\sum_{j \in \mathcal{N}_{i}} a_{i j}$. The graph Laplacian matrix is given by $\mathbf{L}=\mathbf{D}-\mathbf{A}$.

Let the ES system leader output trajectory dynamics be modeled by the following state space model $\Sigma_{0}$ :

$$
\Sigma_{0}:\left\{\begin{array}{l}
\dot{x}_{0}=A_{0} x_{0} \\
y_{0}=C_{0} x_{0}
\end{array}\right.
$$

The ES system follower dynamics are described by $\Sigma_{i}$. Note that both the ultracapacitor and battery ES system followers have SISO dynamics. Each ES system follower has a local cooperative controller that modifies its current reference based on its neighborhood tracking error $e_{i}$ to implement distributed leader tracking synchronization:

$$
e_{i}=\sum_{j \in \mathcal{N}_{i}} a_{i j}\left(y_{j}-y_{i}\right)+g_{i}\left(y_{0}-y_{i}\right) .
$$

The neighborhood tracking error depends on the communication network topology and gives a weighted difference between the ES system output and the outputs of its neighbors. The $i$ th ES system's cooperative controller can be generically described by the following state space model $K_{i}$ :

$$
K_{i}:\left\{\begin{array}{l}
\dot{x}_{r i}=A_{r i} x_{r i}+B_{r i} e_{i} \\
i_{L i}^{*}=K_{r i} x_{r i}+K_{e i} e_{i} .
\end{array}\right.
$$

Combining (6) and (11) the dynamics of the $i$ th ES system follower extended by the local cooperative controller are described by the following state space model $\bar{\Sigma}_{i}$ :

$$
\begin{aligned}
& \bar{\Sigma}_{i}:\left\{\begin{array}{l}
\dot{\bar{x}}_{i}=\bar{A}_{i} \bar{x}_{i}+\bar{B}_{i} e_{i} \\
y_{i}=\bar{C}_{i} \bar{x}_{i}
\end{array} \text { where } \bar{x}_{i}=\left[\begin{array}{ll}
x_{i}^{\mathrm{T}} & x_{r i}^{\mathrm{T}}
\end{array}\right]^{\mathrm{T}}\right. \\
& \bar{A}_{i}=\left[\begin{array}{cc}
A_{i} & B_{i} K_{r i} \\
\mathbf{0} & A_{r i}
\end{array}\right], \bar{B}_{i}=\left[\begin{array}{c}
B_{i} K_{e i} \\
B_{r i}
\end{array}\right], \bar{C}_{i}=\left[\begin{array}{ll}
C_{i} & \mathbf{0}
\end{array}\right] .
\end{aligned}
$$

The overall dynamics of the $N$ extended ES system followers can be described by the following state space model $\overline{\boldsymbol{\Sigma}}$ :

$$
\begin{aligned}
& \overline{\mathbf{\Sigma}}:\left\{\begin{array}{l}
\dot{\overline{\mathbf{x}}}_{i}=\overline{\mathbf{A}} \overline{\mathbf{x}}+\overline{\mathbf{B}} y_{0} \\
\mathbf{y}=\overline{\mathbf{C}} \overline{\mathbf{x}}
\end{array}\right. \text { where } \\
& \overline{\mathbf{x}}=\left[\begin{array}{lll}
\bar{x}_{1}^{\mathrm{T}} & \cdots & \bar{x}_{N}^{\mathrm{T}}
\end{array}\right]^{\mathrm{T}}, \mathbf{y}=\left[\begin{array}{lll}
y_{1} & \cdots & y_{N}
\end{array}\right]^{\mathrm{T}} \\
& \overline{\mathbf{A}}=\operatorname{diag}\left(\bar{A}_{1}, \ldots, \bar{A}_{N}\right)-\operatorname{diag}\left(\bar{B}_{1}, \ldots, \bar{B}_{N}\right)(\mathbf{L}+\mathbf{G}) \overline{\mathbf{C}} \\
& \overline{\mathbf{B}}=\left[\begin{array}{c}
g_{1} \bar{B}_{1} \\
\vdots \\
g_{N} \bar{B}_{N}
\end{array}\right], \overline{\mathbf{C}}=\operatorname{diag}\left(\bar{C}_{1}, \ldots, \bar{C}_{N}\right) .
\end{aligned}
$$

The extended ES system followers satisfy the requirements for leader tracking synchronization (7), (8) if and only if the following conditions are satisfied [34]. 
1) The extended ES system dynamics $\bar{\Sigma}_{i}$ include the leader dynamics $\Sigma_{0}$ in terms of the internal model principle for synchronization.

2) The overall system dynamics of the extended followers $\overline{\boldsymbol{\Sigma}}$ are asymptotically stable.

\section{A. Synchronization Analysis}

On the synchronous trajectory $y_{1}(t)=\cdots=y_{N}(t)=y_{0}(t)$ and the neighborhood tracking errors $e_{1}(t)=\cdots=e_{N}(t)=0$. In the trivial case the leader dynamics $\Sigma_{0}$ are asymptotically stable, and synchronization at $y_{1}(t)=\cdots=y_{N}(t)=y_{0}(t)=$ 0 will be achieved by any followers with stable dynamics and a zero reference. However, in the case where the leader dynamics include eigenvalues with non-negative real part, the leader's output trajectory will not decay. Therefore, to remain synchronised with the leader the extended follower dynamics $\bar{\Sigma}_{i}$ must include an internal model of the leader dynamics $\Sigma_{0}$ [46]. The system $\bar{\Sigma}_{i}$ includes $\Sigma_{0}$ if and only if there exists a state transformation $P$ such that $\bar{A}_{i} P=P A_{0}$ and $\bar{C}_{i} P=C_{0}$ [34]. In this case, an extended follower generates the output trajectory of the leader, if its initial state $\bar{x}_{i}(0)=P x_{0}(0)$. This ensures the first condition for leader tracking synchronization (7) is satisfied.

The ultracapacitor leaders are operated to regulate the DC microgrid bus voltage. In steady state a constant output current is required to regulate the microgrid bus voltage in a DC microgrid. Therefore, for the purpose of describing the output trajectory that the followers must be able to track, the ultracapacitor leaders' voltage dynamics can be modeled by $\Sigma_{0}$ with the following output, state vector and system matrices:

$$
\begin{aligned}
& y_{0}=v_{\text {cap } 0}, x_{0}=\left[\begin{array}{llll}
v_{f 0} & v_{m 0} & v_{s 0} & i_{L c 0}
\end{array}\right]^{\mathrm{T}} \\
& A_{0}=\left[\begin{array}{cc}
A_{\text {cap } 0} & B_{\text {cap } 0} \\
0_{1 \times 3} & 0
\end{array}\right], C_{0}=\left[\begin{array}{ll}
C_{\text {cap } 0} & D_{\text {cap } 0}
\end{array}\right] .
\end{aligned}
$$

The ultracapacitor leader dynamics have two zero eigenvalues modeling the persistent decrease in the ultracapacitor voltage required to sustain a constant output current. However, the ultracapacitor follower dynamics $\Sigma_{i}$ only have a single zero eigenvalue. Therefore, to include an internal model of the leader dynamics, the local cooperative controllers extending the ultracapacitor ES systems must introduce an additional zero eigenvalue. This can be achieved with the following cooperative controller structure $K_{\mathrm{IM} c i}$ :

$$
K_{\mathrm{IM} c i}:\left\{\begin{array}{l}
\dot{x}_{r c i}=e_{i} \\
i_{L c i}^{*}=k_{\mathrm{IM} r c i} x_{r c i}+k_{\mathrm{IM} e c i} e_{i}
\end{array} .\right.
$$

For this cooperative controller, $k_{\mathrm{IM} r c i}$ is the integral gain and $k_{\mathrm{IMeci}}$ is the proportional gain applied to the neighborhood tracking error $e_{i}$ to generate the ES system current reference.

Similarly to the ultracapacitor case, a constant output current is required from the battery leader to regulate the ultracapacitor voltages in steady state. Therefore, the battery leaders' SoC dynamics can be modeled by $\Sigma_{0}$ with the following output, state vector and system matrices:

$$
\begin{aligned}
& y_{0}=S o C_{0}, x_{0}=\left[\begin{array}{ll}
S o C_{0} & i_{L b 0}
\end{array}\right]^{\mathrm{T}} \\
& A_{0}=\left[\begin{array}{cc}
0 & B_{\text {batt0 }} \\
0 & 0
\end{array}\right], C_{0}=\left[\begin{array}{ll}
1 & 0
\end{array}\right] .
\end{aligned}
$$

The same local cooperative controller structure (denoted $K_{\mathrm{IM} b i}$ ) can be used to provide the additional zero eigenvalue necessary for the battery ES system followers to include the battery leader dynamics.

\section{B. Stability Analysis}

The synchronization error between the ES system leader and the $i$ th ES system follower is given by $e_{s i}(t)=y_{0}(t)-y_{i}(t)$. Given the overall ES system follower dynamics (13), the overall synchronization error dynamics are described by the following state space model $\boldsymbol{\Sigma}_{e}[34]$ :

$$
\boldsymbol{\Sigma}_{e}:\left\{\begin{array}{l}
\dot{\mathbf{x}}_{e}=\overline{\mathbf{A}} \mathbf{x}_{e} \\
\mathbf{e}_{s}=-\overline{\mathbf{C}} \mathbf{x}_{e}
\end{array} \text { where } \mathbf{e}_{s}=\left[e_{s 1} \cdots e_{s N}\right]^{\mathrm{T}} .\right.
$$

The second condition for leader tracking synchronization (8) requires that $\boldsymbol{\Sigma}_{e}$ is asymptotically stable.

This condition is significantly simplified in the special case where the communication network does not contain any cycles. In this case leader tracking synchronization (7), (8) is achieved if and only if the following conditions are met [34].

1) The communication network has a spanning tree with the ES system leader as the root node.

2) The extended ES system follower dynamics $\bar{\Sigma}_{i}$ include the leader dynamics $\Sigma_{0}$.

3) For each ES system follower the local closed loop extended system dynamics $\left(\bar{A}_{i}-\bar{B}_{i} \bar{C}_{i}, \bar{B}_{i}, \bar{C}_{i}\right)$ are asymptotically stable.

\section{Agent Controller Design}

Each type of ES system agent is responsible for utilizing stored energy to regulate a particular variable in the microgrid. For each type of agent, transfer functions are provided between the reference signal and its regulated output. Within the requirements of controllers providing leader tracking synchronization, standard PI controller tuning techniques can be applied to the controllers of each agent to provide a desirable trade-off between the transient response for the regulated quantity and the ES device output current.

1) Ultracapacitor Leader: The ultracapacitor leader uses its stored energy to regulate its local bus voltage to the microgrid voltage reference.

Each ES system agent uses the inner current loop control strategy from [40]. The inner current loop should be designed to have a bandwidth on the order of 10 times the outer control loop, so they are decoupled. This is achievable due to the relatively small DC-DC converter inductor size. For each of the ultracapacitors, the closed loop inductor current regulation transfer function is given by

$$
\begin{aligned}
\frac{i_{L c 0, i}}{i_{L c 0, i}^{*}} & =G_{L c 0, i}^{c l}, \text { where } G_{L c 0, i}^{c l}=\frac{K_{I c 0, i} G_{L c 0}}{1+K_{I c 0, i} G_{L c 0, i}} \\
K_{I c 0, i} & =\frac{k_{I I c 0, i}}{s}+k_{I P c 0, i}, G_{L c 0, i}=\frac{1}{r_{L c 0, i}+s L_{c 0, i}} .
\end{aligned}
$$

The ultracapacitor leader closed loop bus voltage regulation transfer function is given by 


$$
\begin{aligned}
& \frac{v_{o 0}}{v^{m g}}=\frac{K_{V c 0} G_{C c 0} G_{L c 0}^{c l}}{1+K_{V c 0} G_{C c 0} G_{L c 0}^{c l}}, \\
& \text { where } K_{V c 0}=\frac{k_{V I c 0}}{s}+k_{V P c 0}, G_{C c 0}=\frac{1+s r_{c c 0} C_{c 0}}{s C_{c 0}} .
\end{aligned}
$$

2) Ultracapacitor Followers: The ultracapacitor followers attempt to track the ultracapacitor leader voltage based on information received from their neighbors. The local neighborhood tracking error $e_{i}$ is given by

$$
e_{i}=\sum_{j \in \mathcal{N}_{i}} a_{i j} v_{\mathrm{cap} j}+g_{i} v_{\mathrm{cap} 0}-\left(d_{i}+g_{i}\right) v_{\mathrm{cap} i} .
$$

In the cycle-less communication network case, the transfer function between the ultracapacitor voltage of a neighboring ES system $j$, and the $i$ th ultracapacitor's voltage is given by

$$
\begin{aligned}
& \frac{v_{\mathrm{cap} i}}{v_{\mathrm{cap} j}}=\frac{a_{i j} G_{\mathrm{vcap} i} G_{L c i}^{c l} K_{\mathrm{IM} c i}}{1+G_{\mathrm{vcap} i} G_{L c i}^{c l} K_{\mathrm{IM} c i}\left(d_{i}+g_{i}\right)}, \\
& \text { where } K_{\mathrm{IM} c i}=\frac{k_{\mathrm{IM} r c i}}{s}+k_{\mathrm{IM} e c i} .
\end{aligned}
$$

$G_{\mathrm{vcap} i}=v_{\text {cap } i} / i_{L c i}$ is the transfer function between the inductor current and ultracapacitor voltage. $G_{\mathrm{vcap} i}$ is provided in the Appendix.

3) Battery Leader: The battery leader uses its stored energy to regulate the ultracapacitor leader voltage to a desired reference. Let the buses of the battery and ultracapacitor leaders be connected by a line with resistance and inductance $r_{\text {line } 0}, L_{\text {line } 0}$. Then the ultracapacitor leader voltage regulation transfer function is given by

$$
\begin{aligned}
& \frac{v_{\text {cap } 0}}{v_{\text {cap }}^{*}}=\frac{G_{\mathrm{vcap} 0} G_{\mathrm{net} 0} G_{L b 0}^{c l} K_{\mathrm{Vuc} 0}}{1+G_{\mathrm{vcap} 0} G_{\mathrm{net} 0} G_{L b 0}^{c l} K_{\mathrm{Vuc} 0}}, \\
& \text { where } K_{\mathrm{Vuc} 0}=\frac{k_{\mathrm{Vuc} I 0}}{s}+k_{\mathrm{Vuc} P 0} .
\end{aligned}
$$

$G_{\text {net } 0}=i_{L c 0} / i_{o b 0}$ is the transfer function between the battery leader output current and the ultracapacitor leader inductor current. $G_{\text {neto }}$ is provided in the Appendix. For the battery ES systems, the closed loop inductor current regulation transfer functions are given by

$$
\begin{aligned}
\frac{i_{L b 0, i}}{i_{L b 0, i}^{*}} & =G_{L b 0, i}^{c l}, \text { where } G_{L b 0, i}^{c l}=\frac{K_{I b 0, i} G_{L c 0}}{1+K_{I c 0, i} G_{L b 0, i}} \\
K_{I b 0, i} & =\frac{k_{I I b 0, i}}{s}+k_{I P b 0, i}, G_{L b 0, i}=\frac{1}{r_{L b 0, i}+s L_{b 0, i}} .
\end{aligned}
$$

4) Battery Followers: The battery followers attempt to track the battery leader SoC based on information received from their neighbors. In the cycle-less communication network case, the transfer function between the SoC of a neighboring battery $j$ and the $i$ th battery's SoC is given by

$$
\begin{aligned}
& \frac{S o C_{i}}{S o C_{j}}=\frac{a_{i j} G_{\mathrm{SoC} i} G_{L b i}^{c l} K_{\mathrm{IM} b i}}{1+G_{\mathrm{SoC} i} G_{L b i}^{c l} K_{\mathrm{IM} b i}\left(d_{i}+g_{i}\right)}, \\
& \text { where } G_{\mathrm{SoC} i}=\frac{S o C_{i}}{i_{L b i}}=-\frac{\eta_{i}}{s C_{n i}} .
\end{aligned}
$$

5) Grid Connected Converter: The grid connected converter adjusts its output power to regulate the SoC of the battery leader to a desired reference during grid connected mode. For the purpose of outer loop controller design, the inner current loop dynamics of a three phase voltage source converter with high switching frequency, and direct power control can be described by a low-pass transfer function with time constant $\tau_{s}$ on the order of one switching period [47]:

$$
G_{I d c}^{\mathrm{ac} / \mathrm{dc}}=\frac{i_{o \mathrm{ac} / \mathrm{dc}}}{P_{\mathrm{ac} / \mathrm{dc}}^{*}}=\frac{1 / \bar{v}_{o \mathrm{ac} / \mathrm{dc}}}{1+s \tau_{s}} .
$$

Let the buses of the grid connected converter and ultracapacitor leader be connected by a line with resistance and inductance $r_{\text {line }}^{\mathrm{ac} / \mathrm{dc}}, L_{\text {line }}^{\mathrm{ac} / \mathrm{dc}}$. Then the closed loop battery leader SoC regulation transfer function is given by

$$
\begin{aligned}
& \frac{S o C_{0}}{S o C^{*}}=\frac{G_{S o C 0} G_{a c / d c, L b 0} G_{I d c}^{\mathrm{ac} / \mathrm{dc}} K_{P^{*}}^{\mathrm{ac} / \mathrm{dc}}}{1+G_{S o C 0} G_{a c / d c}, L b 0} G_{I d c}^{\mathrm{ac} / \mathrm{dc}} K_{P^{*}}^{\mathrm{ac} / \mathrm{dc}} \\
& \text { where } K_{P^{*}}^{\mathrm{ac} / \mathrm{dc}}=\frac{k_{P^{*} I}^{\mathrm{ac} / \mathrm{dc}}}{s}+k_{P^{*} P}^{\mathrm{ac} / \mathrm{dc}} .
\end{aligned}
$$

$G_{a c / d c, L b 0}=i_{L b 0} / i_{o}^{a c / d c}$ is the transfer function between the grid converter output current and the battery leader inductor current. $G_{a c / d c, L b 0}$ is provided in the Appendix.

\section{Case Studies}

Simulations were carried out to demonstrate the performance of the proposed control strategy for a DC datacenter microgrid. Case study 1 demonstrates the performance of the proposed control strategy for a 380 VDC microgrid datacenter, when there is a sudden transition from grid connected to islanded mode. For Case Study 2, variable generation sources are introduced to demonstrate the performance for bidirectional power flow. In Case Study 3 the microgrid has two ultracapacitor leaders and two battery leaders, for added reliability. Proper operation is maintained when one of the ultracapacitor leaders fail.

The datacenter microgrid used for Case Studies 1 and 2 is shown in Fig. 7. The same power network is used for Case Study 3 , but with extra communication links to support the multiple ultracapacitor and battery leaders, as shown in Fig. 20. Based on the ETSI EN 300 132-3-1 standard the datacenter microgrid voltage limits are set to $380 \mathrm{~V} \pm 5 \%$ ( $360 \mathrm{~V}$ to $400 \mathrm{~V}$ ) [8]. The datacenter has a hierarchical power distribution system based on the typical architecture for 380VDC datacenters presented in [48]. A grid connected converter provides an interface with the main grid at bus 0 . The datacenter has 10 load buses, each corresponding to a server rack. The load buses are connected to bus 0 by $15 \mathrm{~m} 5 \mathrm{~mm}^{2} \mathrm{CU}$ cable. Each load bus has a variable 2-kW load and an ultracapacitor ES to provide high power density ES. The nominal capacitance of the ultracapacitors is $500 \mathrm{~F}$ for load buses $1 \mathrm{c}$ to $5 \mathrm{c}$ and $250 \mathrm{~F}$ for load buses $6 \mathrm{c}$ to $10 \mathrm{c}$. Bulk ES is provided by three $20-\mathrm{kWh}$ lithium-ion battery ES systems, each connected by $3 \mathrm{~m} 5 \mathrm{~mm}^{2} \mathrm{CU}$ cable to bus 0 .

For Case Study 1 and 2, directed communication links provide a spanning tree between the ultracapacitors, with the ultracapacitor leader at bus $1 \mathrm{c}$ as the root node. Similarly, a spanning tree is provided between the batteries, with the battery leader at 


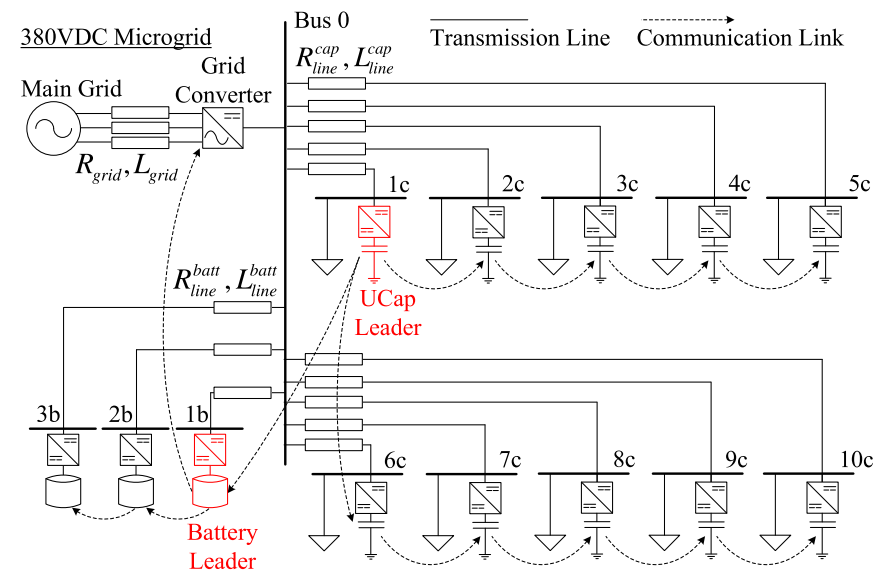

Fig. 7. Case Study 1 and 2: 380 VDC datacenter microgrid.

TABLE I

SIMULATION PARAMETERS

\begin{tabular}{|c|c|c|c|c|c|}
\hline \multicolumn{6}{|c|}{ DC Microgrid } \\
\hline$\overline{v^{m g}}$ & $380 \mathrm{~V}$ & $L_{\text {line }}^{\text {batt }}$ & $10 \mu \mathrm{H}$ & $R_{\text {line }}^{\text {batt }}$ & $10 \mathrm{~m} \Omega$ \\
\hline$\Delta v$ & $20 \mathrm{~V}$ & $L_{\text {line }}^{\text {cap }}$ & $10 \mu \mathrm{H}$ & $R_{\text {line }}^{\text {cap }}$ & $50 \mathrm{~m} \Omega$ \\
\hline \multicolumn{6}{|c|}{ Grid Connected Converter } \\
\hline$S o C^{*}$ & $100 \%$ & $k_{P^{*} P}^{\mathrm{ac} / \mathrm{dc}}$ & $25 \times 10^{4}$ & $k_{P^{*} I}^{\mathrm{ac} / \mathrm{dc}}$ & 50 \\
\hline$f_{s}$ & $10 \mathrm{kHz}$ & $L_{\text {grid }}$ & $100 \mu \mathrm{H}$ & $R_{\text {grid }}$ & $10 \mathrm{~m} \Omega$ \\
\hline$C_{\text {filt }}$ & $100 \mu \mathrm{F}$ & $L_{\text {filt }}$ & $50 \mu \mathrm{H}$ & $R_{\text {filt }}$ & $50 \mathrm{~m} \Omega$ \\
\hline$C_{d c}^{a c / d c}$ & $1 \mathrm{mF}$ & $r_{c d c}^{a c / d c}$ & $6 \mathrm{~m} \Omega$ & & \\
\hline \multicolumn{6}{|c|}{ Ultracapacitor ES Systems } \\
\hline$\overline{v_{\text {cap }}^{*}}$ & $80 \mathrm{~V}$ & $f_{s c 0, i}$ & $16 \mathrm{kHz}$ & $L_{c 0, i}$ & $50 \mu \mathrm{H}$ \\
\hline$r_{L c 0, i}$ & $10 \mathrm{~m} \Omega$ & $C_{c 0, i}$ & $1 \mathrm{mF}$ & $r_{c c 0, i}$ & $6 \mathrm{~m} \Omega$ \\
\hline$C_{f 1-5 c}$ & $525 \mathrm{~F}$ & $C_{m 1-5 c}$ & $47.3 \mathrm{~F}$ & $C_{s 1-5 c}$ & $124 \mathrm{~F}$ \\
\hline$R_{f 1-5 c}$ & $3.3 \mathrm{~m} \Omega$ & $R_{m 1-5 c}$ & $4.55 \Omega$ & $R_{s 1-5 c}$ & $11.90 \Omega$ \\
\hline$C_{f 6-10 c}$ & $262 \mathrm{~F}$ & $C_{m 6-10 c}$ & $23.7 \mathrm{~F}$ & $C_{s 6-10 c}$ & $62.0 \mathrm{~F}$ \\
\hline$R_{f 6-10 c}$ & $6.7 \mathrm{~m} \Omega$ & $R_{m 6-10 c}$ & $9.09 \Omega$ & $R_{s 6-10 c}$ & $23.80 \Omega$ \\
\hline$k_{I P c 0, i}$ & $5 \times 10^{-1}$ & $k_{I I c 0, i}$ & $5 \times 10^{-2}$ & $k_{V P c 0}$ & $1 \times 10^{-1}$ \\
\hline$k_{V I c 0}$ & $1 \times 10^{-1}$ & $k_{\mathrm{IMeci}}$ & -1 & $k_{\mathrm{IM} r c i}$ & $-2 \times 10^{-3}$ \\
\hline $\mathrm{T}_{F}$ & $1 \times 10^{-3}$ & & & & \\
\hline \multicolumn{6}{|c|}{ Battery ES Systems } \\
\hline$\overline{C_{n 0, i}}$ & $6 \times 10^{5} \mathrm{As}$ & $\eta_{0, i}$ & $100 \%$ & $E_{\text {batt } 0 ; 0, i}$ & $120 \mathrm{~V}$ \\
\hline$f_{s b 0, i}$ & $16 \mathrm{kHz}$ & $r_{\text {batt } 0, \mathrm{i}}$ & $5 \mathrm{~m} \Omega$ & $\mathrm{K}_{\text {batt } 0, \mathrm{i}}$ & $3.8 \mathrm{mV} / \mathrm{Al}$ \\
\hline$L_{b 0, i}$ & $50 \mu \mathrm{H}$ & $r_{L b 0, i}$ & $10 \mathrm{~m} \Omega$ & $C_{b 0, i}$ & $1 \mathrm{mF}$ \\
\hline$r_{c b 0, i}$ & $6 \mathrm{~m} \Omega$ & $k_{I P b 0, i}$ & $5 \times 10^{-1}$ & $k_{I I b 0, i}$ & $5 \times 10^{-2}$ \\
\hline$k_{\mathrm{Vuc} P 0}$ & 1 & $k_{\mathrm{Vuc} I 0}$ & $5 \times 10^{-3}$ & $k_{\mathrm{IM} e b 0, i}$ & $-1 \times 10^{3}$ \\
\hline$k_{\mathrm{IM} r b 0, i}$ & -1 & & & & \\
\hline
\end{tabular}

bus $1 \mathrm{~b}$ as the root node. A communication link allows the battery leader to receive the ultracapacitor leader voltage, so that it can be regulated to the $80 \mathrm{~V}$ reference. A communication link from the leader battery to the grid connected converter allows the converter to regulate the battery's $\mathrm{SoC}$ to the $100 \%$ reference during grid connected mode. The simulation parameters are shown in Table I. The communication topology for Case Study 3 is described in Section V-C.

\section{A. Case Study 1-Grid Connected and Islanded Mode}

Fig. 8 shows 10 minutes of the periodic load profiles used for Case Study 1. To clearly demonstrate the operation of the proposed control strategy the practice of characterizing datacenter load variability as a series of peaks and valleys is adopted [49]. Based on statistical analysis of datacenter load magnitudes [50]

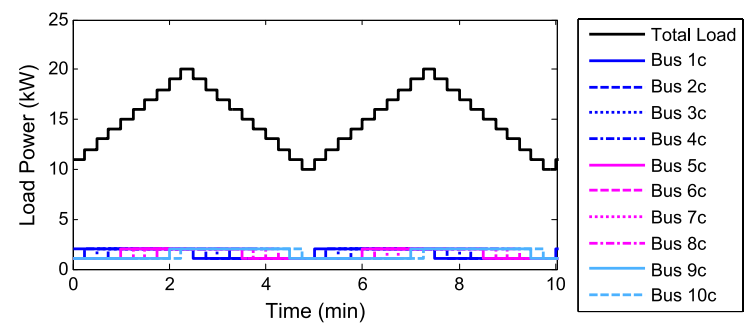

Fig. 8. Case Study 1 and 3: DC microgrid load profiles over $10 \mathrm{~min}$.

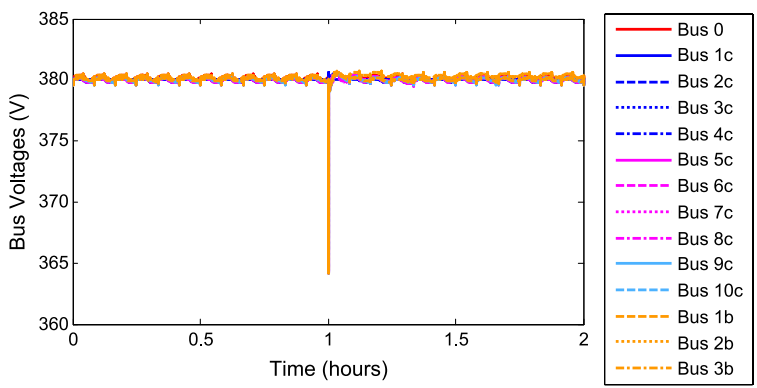

Fig. 9. Case Study 1-Grid Connected and Islanded Mode: DC microgrid bus voltages.

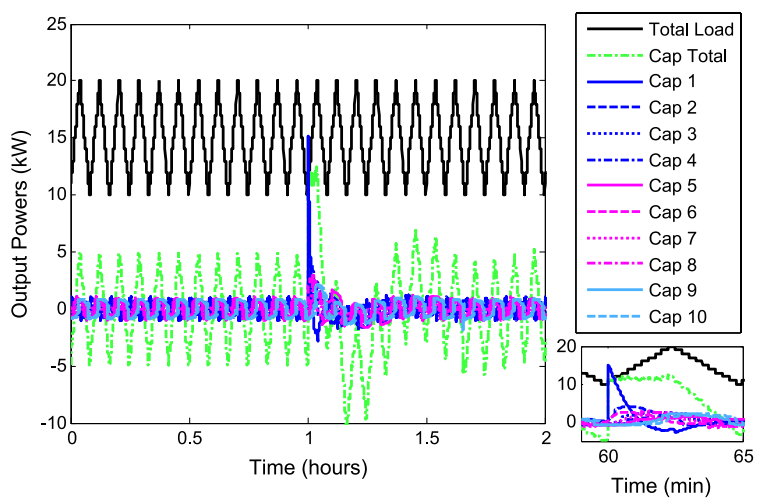

Fig. 10. Case Study $1-$ Grid Connected and Islanded Mode: Total microgrid load and ultracapacitor ES system output powers.

and peak/valley durations [49] the loads are characterized as varying between $1 \mathrm{~kW}$ and $2 \mathrm{~kW}$ every $2.5 \mathrm{~min}$. The load pulses have phase offsets from 0 to $135 \mathrm{~s}$, so that the total load varies between $10 \mathrm{~kW}$ and $20 \mathrm{~kW}$ with a 5 -min period.

1) Grid Connected Operation: Hour 0 to 1: The datacenter microgrid begins in grid connected mode. As shown in Fig. 9, the bus voltages are regulated around the desired $380 \mathrm{~V}$ reference by the ultracapacitor leader. The ultracapacitors supply the high frequency load, as shown in Fig. 10. On a slower time-scale the battery leader sets its current reference to regulate the ultracapacitor leader voltage. The grid connected converter injects power to maintain the battery leader at $100 \%$ SoC, and thus the battery leader output power is regulated to zero, as shown in Fig. 11. The peak $20 \mathrm{~kW}$ load is shaved and the maximum grid connected converter output power is $15.2 \mathrm{~kW}$. The leader tracking synchronization protocols implemented by the ES systems maintain voltage balancing between the ultracapacitors and $\mathrm{SoC}$ balancing between the batteries, as shown in Figs. 12 and 13. 


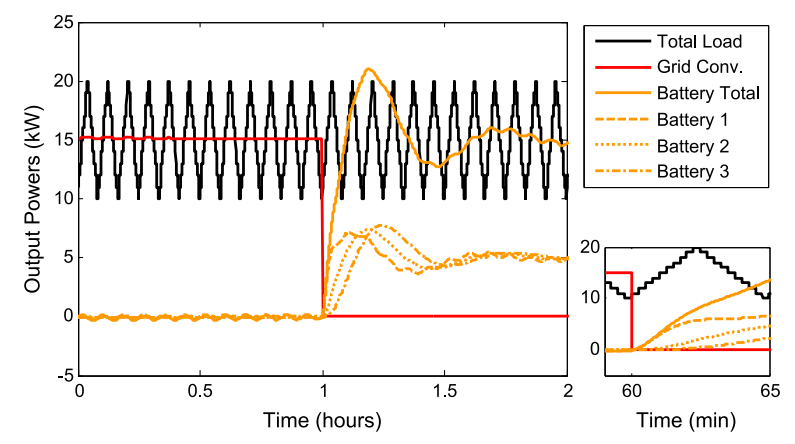

Fig. 11. Case Study $1-$ Grid Connected and Islanded Mode: Total microgrid load, grid connected converter output power and battery ES system output powers.

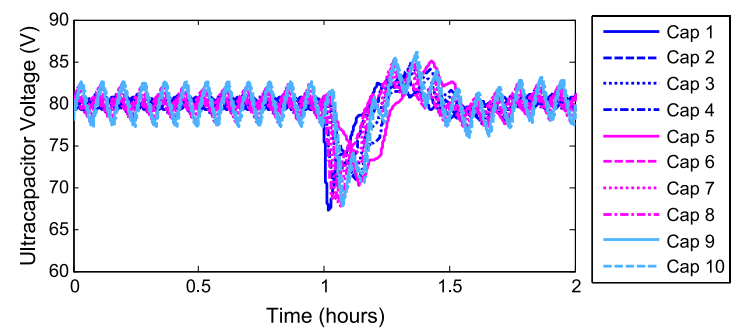

Fig. 12. Case Study 1-Grid Connected and Islanded Mode: Ultracapacitor voltages.

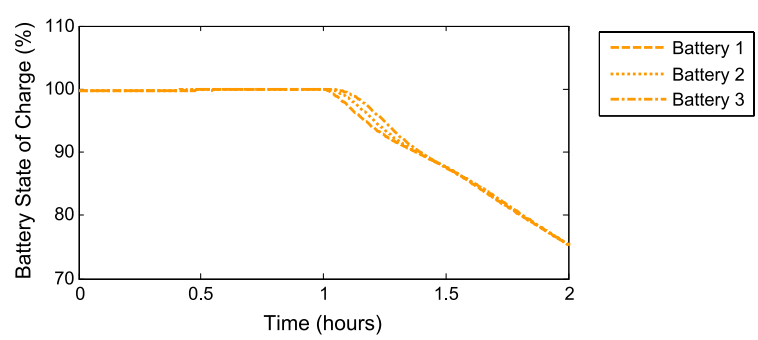

Fig. 13. Case Study 1 - Grid Connected and Islanded Mode: Battery states of charge.

2) Islanded Operation: Hour 1 to 2: After $1 \mathrm{~h}$, sudden disconnection of the grid connected converter causes its output power to fall to zero, as shown in Fig. 11, and the DC microgrid enters islanded mode. The sudden power imbalance causes the DC microgrid bus voltages to fall as shown in Fig. 9. The ultracapacitor leader responds by increasing its output power as shown in Fig. 10, so that the minimum bus voltage reached is $364.1 \mathrm{~V}$, and the microgrid voltage limits are not violated. The ultracapacitor followers synchronize to the ultracapacitor leader's voltage, so that they share the load necessary to restore the microgrid power balance. On a slower time-scale the battery leader increases its output power to regulate the ultracapacitor leader voltage, which reaches a minimum level of $67 \mathrm{~V}$. The leader tracking synchronization protocol between the batteries then restores SoC balancing, as shown in Fig. 13. After approximately $30 \mathrm{~min}$, the battery followers have synchronised with the leader's SoC trajectory and the low frequency load is equally shared between them.

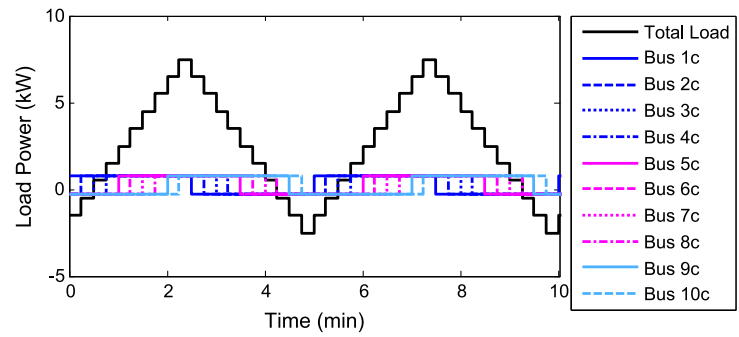

Fig. 14. Case Study 2-Bidirectional Power Flow: DC microgrid load profiles over $10 \mathrm{~min}$.

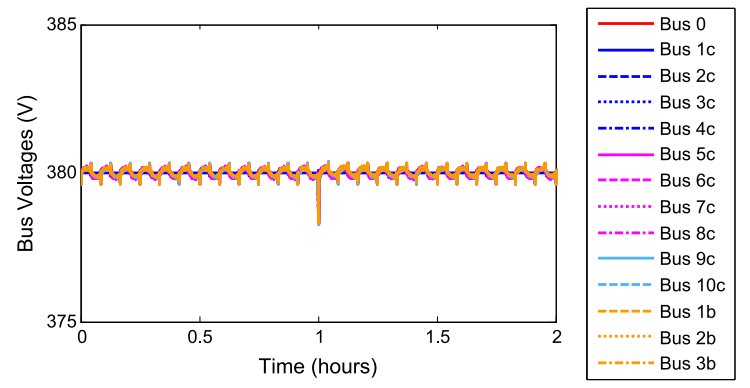

Fig. 15. Case Study 2-Bidirectional Power Flow: DC microgrid bus voltages.

\section{B. Case Study 2-Bidirectional Power Flow}

To demonstrate the performance of the proposed control strategy for bidirectional power flow, generation sources are introduced at the load buses. Fig. 14 shows 10 minutes of the new load profile. The aggregated load at each bus varies between injecting $250 \mathrm{~W}$ and absorbing $750 \mathrm{~W}$, so the total load varies between $-2.5 \mathrm{~kW}$ and $7.5 \mathrm{~kW}$, with a 5 -min period.

For the first hour of operation the microgrid is in grid connected mode. As shown in Figs. 16 and 17, the ultracapacitors supply the high frequency load, while the grid connected converter power varies between 2.5 and $2.6 \mathrm{~kW}$, keeping the batteries at $100 \% \mathrm{SoC}$. After one hour, the grid connected converter is suddenly disconnected and the microgrid enters islanded operation. The resulting power imbalance is less severe than Case 1 , and the microgrid bus voltage falls by only $1.8 \mathrm{~V}$, as shown in Fig. 15. As shown in Fig. 18, the ultracapacitor voltages reach a minimum level of $76 \mathrm{~V}$ before the battery ES systems inject power to restore them to the $80 \mathrm{~V}$ reference. SoC balancing between the battery ES systems is restored after approximately 30 min, as shown in Fig. 19.

\section{Case Study 3-Multiple Leaders}

Multiple ultracapacitor and battery leaders can be introduced into the microgrid to remove potential single points of failure. Load sharing between the ultracapacitor leaders responsible for voltage regulation is achieved through V-I droop control, as described in Section II-A. Based on the worst case microgrid load of $20 \mathrm{~kW}\left(i_{L c 0}^{\max }=250 \mathrm{~A}\right)$ and the maximum microgrid voltage deviation, $\Delta v=20 \mathrm{~V}$, the droop coefficient is selected as $R_{\text {droop }}=0.08 \mathrm{~V} / \mathrm{A}$. SoC balancing between the battery leaders is achieved by augmenting them with the battery follower current control strategy, and ensuring there is a spanning tree between them. 


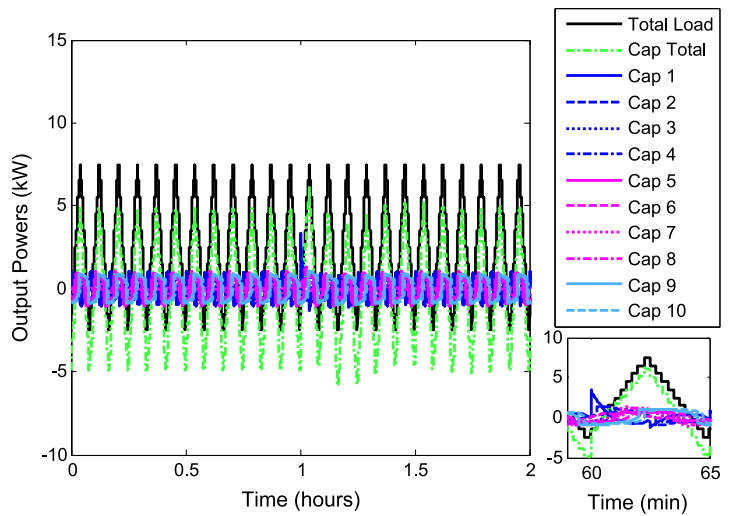

Fig. 16. Case Study 2-Bidirectional Power Flow: Total microgrid load and ultracapacitor ES system output powers.

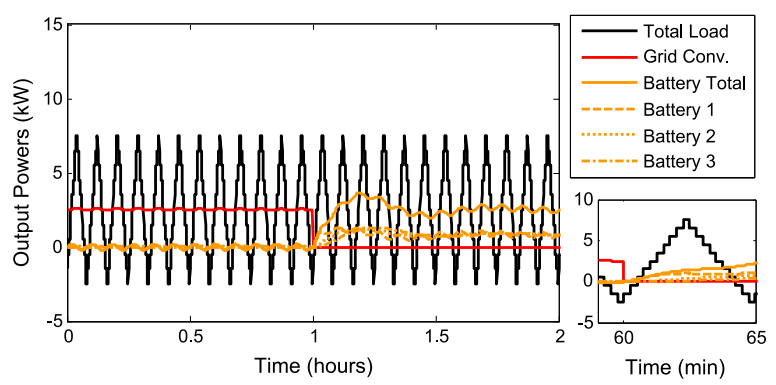

Fig. 17. Case Study 2-Bidirectional Power Flow: Total microgrid load, grid connected converter output power and battery ES system output powers.

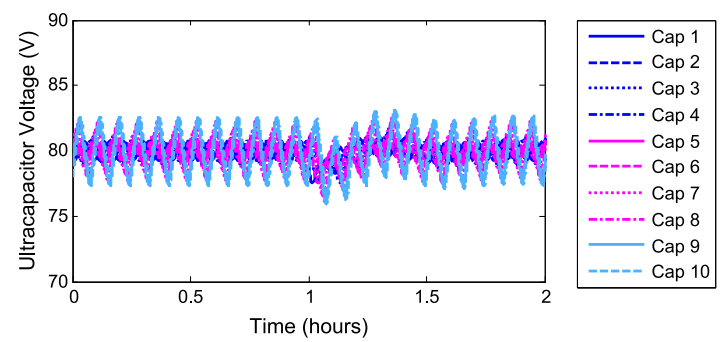

Fig. 18. Case Study 2-Bidirectional Power Flow: Ultracapacitor voltages.

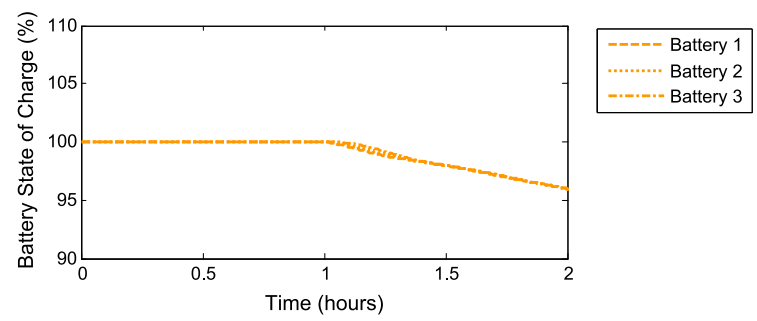

Fig. 19. Case Study 2-Bidirectional Power Flow: Battery states of charge.

The DC microgrid, updated for Case Study 3, is shown in Fig. 20. The ultracapacitor leaders are at buses $1 \mathrm{c}$ and $6 \mathrm{c}$, and the battery leaders are at buses $1 \mathrm{~b}$ and $3 \mathrm{~b}$. New communication links have been added from $1 \mathrm{c}$ to $7 \mathrm{c}$, and from $6 \mathrm{c}$ to $2 \mathrm{c}$, ensuring there is a spanning tree from each ultracapacitor leader to the ultracapacitor followers. Communication links have also been added from each of the ultracapacitor leaders to each of the battery leaders, and from the battery leaders to the grid connected converter. Finally, the links between the battery ES sys-

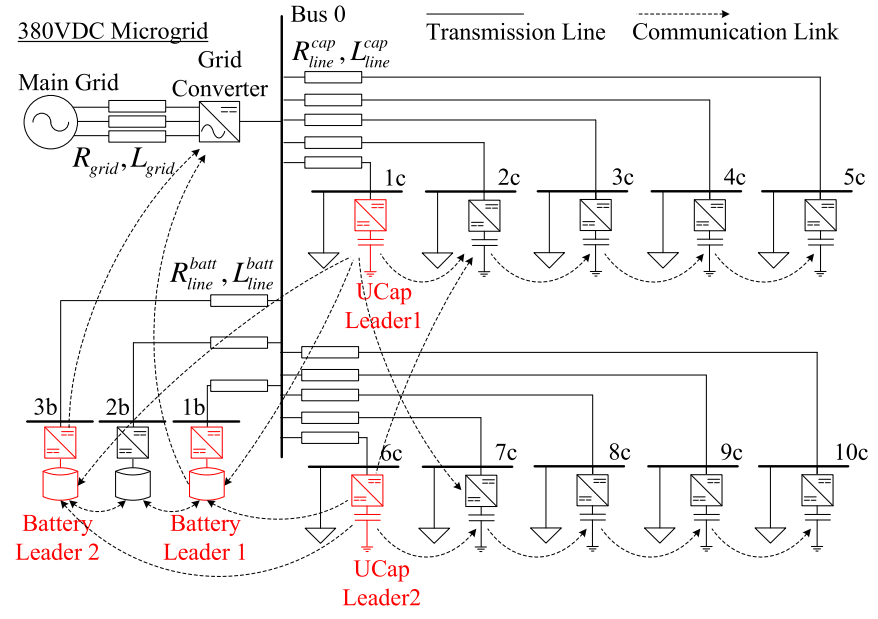

Fig. 20. Case Study 3: 380VDC datacenter microgrid with two ultracapacitor leaders and two battery leaders.

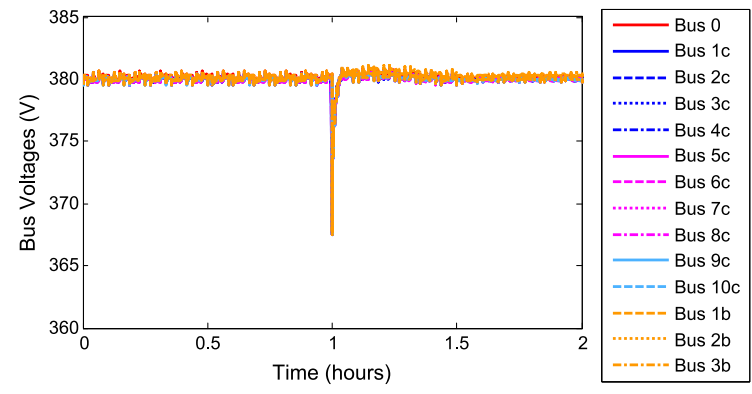

Fig. 21. Case Study 3-Multiple Leaders: DC microgrid bus voltages.

tems have been made bidirectional to provide a spanning tree between the leaders.

The same load profile as Case 1 was used, shown in Fig. 8. For the first hour of operation, the microgrid is in grid connected mode. As shown in Fig. 21, the microgrid bus voltages vary between $379.5 \mathrm{~V}$ and $380.6 \mathrm{~V}$, due to the V-I droop characteristic introduced to provide current sharing between the two ultracapacitor leaders.

The grid connected converter was suddenly disconnected after one hour. The ultracapacitor leaders share the load required to restore the microgrid power balance, as shown in Fig. 22. The minimum voltage reached by the microgrid is $367.5 \mathrm{~V}$, still above the minimum microgrid voltage of 360 $\mathrm{V}$. Note that of the two ultracapacitor leaders, $6 \mathrm{c}$ has a lower capacity, and reaches a minimum voltage of $68 \mathrm{~V}$, as shown in Fig. 24. Both battery leaders share the output power required to restore the ultracapacitor voltages, as shown in Fig. 23. This reduces the maximum $\mathrm{SoC}$ deviation between the batteries to 0.5\%, as shown in Fig. 25.

After one and a half hours, ultracapacitor leader 1c is suddenly disconnected from the network. As shown in Fig. 21, bus voltage regulation is not negatively impacted, and proper operation is maintained.

\section{CONCLUSION}

In this paper a multi-agent cooperative control strategy has been presented for coordinating power sharing between ultracapacitors and batteries distributed throughout a DC microgrid. 

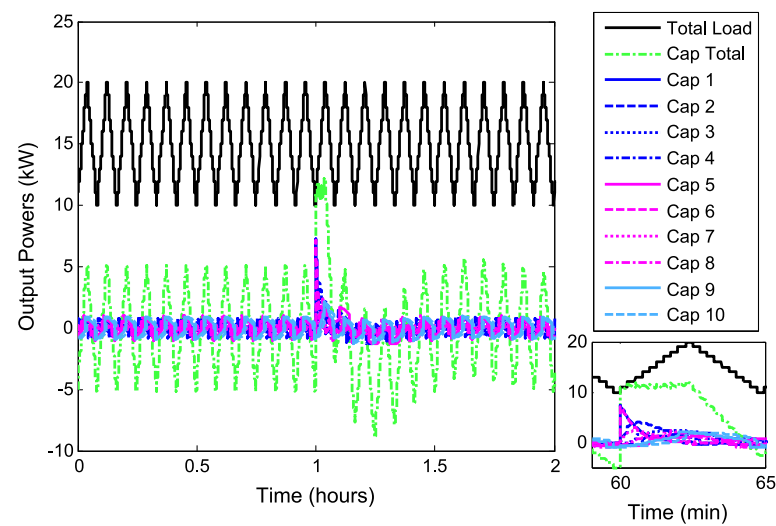

Fig. 22. Case Study 3-Multiple Leaders: Total microgrid load and ultracapacitor ES system output powers.

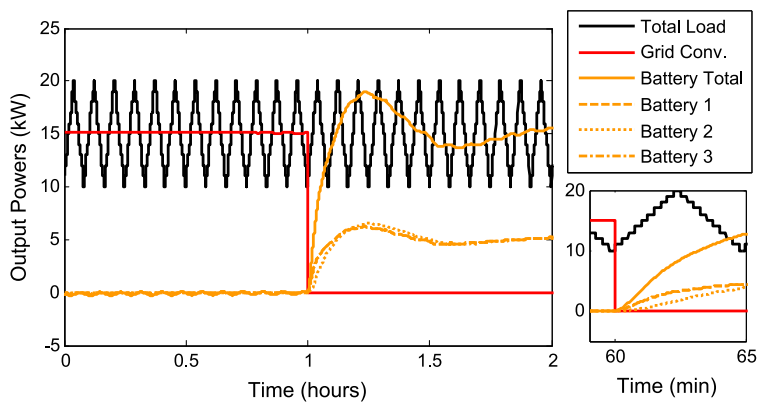

Fig. 23. Case Study 3-Multiple Leaders: Total microgrid load, grid connected converter output power and battery ES system output powers.

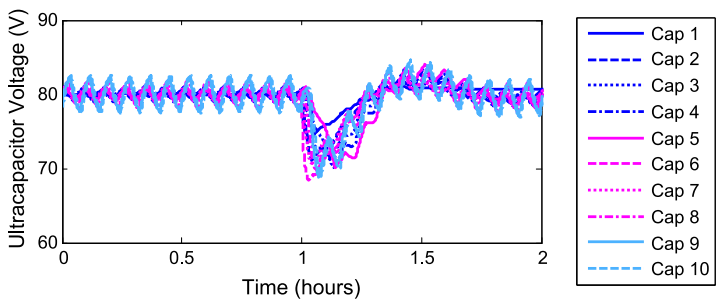

Fig. 24. Case Study 3-Multiple Leaders: Ultracapacitor voltages.

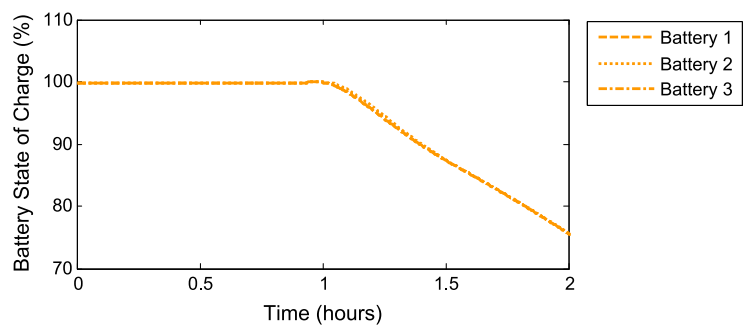

Fig. 25. Case Study 3-Multiple Leaders: Battery states of charge.

Without requiring a central controller, the ultracapacitors are utilized for power quality regulation, while the batteries are utilized for bulk energy storage. The only communication requirement is a sparse communication network providing spanning trees from the ultracapacitor and battery leaders to their respective followers. The proposed control strategy is able to capture the benefits offered by using multiple energy storage technologies, while the distributed control structure maintains the advan- tages in terms of reliability, flexibility and scalability offered by using multiple spatially distributed storage devices.

\section{APPENDIX}

$G_{\mathrm{vcap} i}=v_{\mathrm{cap} i} / i_{L c i}$ is the transfer function between the inductor current and ultracapacitor voltage:

$$
\begin{aligned}
G_{\mathrm{vcap} i}= & -\frac{a_{3} s^{3}+a_{2} s^{2}+a_{1} s+a_{0}+1}{A_{3} s^{3}+A_{2} s^{2}+A_{1} s}, \\
a_{3}= & C_{m i} R_{m i} C_{f i} R_{f i} C_{s i} R_{s i}, \\
a_{2}= & C_{m i} R_{m i} C_{f i} R_{f i}+C_{m i} R_{m i} C_{s i} R_{s i} \\
& +C_{f i} R_{f i} C_{s i} R_{s i} \\
a_{1}= & C_{m i} R_{m i}+C_{f i} R_{f i}+C_{s i} R_{s i}, \\
A_{3}= & C_{s i} C_{m i} R_{m i} C_{f i} R_{f i}+C_{f i} C_{m i} R_{m i} C_{s i} R_{s i} \\
& +C_{m i} C_{f i} R_{f i} C_{s i} R_{s i}, \\
A_{2}= & C_{s i} C_{m i} R_{m i}+C_{s i} C_{f i} R_{f i}+C_{f i} C_{s i} R_{s i} \\
& +C_{f i} C_{m i} R_{m i}+C_{m i} C_{f i} R_{f i}+C_{m i} C_{s i} R_{s i}, \\
A_{1}= & C_{f i}+C_{m i}+C_{s i}
\end{aligned}
$$

$G_{\text {net0 }}=i_{L c 0} / i_{o b 0}$ is the transfer function between the battery leader output current and the ultracapacitor leader inductor current:

$$
\begin{aligned}
& G_{\text {net } 0}=-\frac{\left(\frac{\bar{v}_{c c 0}}{\bar{v}_{\text {cap } 0}}\right) G_{L c 0}^{c l} K_{V c 0} G_{C c 0} G_{\text {line } 0} G_{C b 0}}{G_{L c 0}^{c l} K_{V c 0} G_{C c 0} G_{\text {line0 } 0} G_{C b 0}+G_{\text {line } 0} G_{C b 0}+} \\
& G_{\text {line } 0} G_{C c 0}+G_{L c 0}^{c l} K_{V c 0} G_{C c 0}+1 \\
& G_{\text {line0 }}= \frac{1}{r_{\text {line } 0}+s L_{\text {line } 0}}, G_{C b 0}=\frac{1+s r_{c b 0} C_{b 0}}{s C_{b 0}} .
\end{aligned}
$$

$G_{a c / d c, L b 0}=i_{L b 0} / i_{o}^{a c / d c}$ is the transfer function between the grid converter output current and the battery leader inductor current:

$$
G_{a c / d c, L b 0}=\frac{-\left(\frac{\bar{v}_{\text {ob } 0}}{\bar{v}_{\mathrm{batt} 0}}\right) G_{L b 0}^{c l} K_{\mathrm{Vuc} 0} G_{\mathrm{vcap} 0} G_{\mathrm{net}}^{\mathrm{ac} / \mathrm{dc}}}{1+G_{L b 0}^{c l} K_{\mathrm{Vuc} 0} G_{\mathrm{vcap} 0} G_{\mathrm{net} 0}} .
$$

$G_{\text {net }}^{\mathrm{ac} / \mathrm{dc}}=i_{L c 0} / i_{o}^{a c / d c}$ is the transfer function between the grid converter output current and the ultracapacitor leader inductor current:

$$
\begin{array}{r}
G_{\text {net }}^{\mathrm{ac} / \mathrm{dc}}=-\frac{\left(\frac{\bar{v}_{o c 0}}{\bar{v}_{\text {cap } 0}}\right) G_{L c 0}^{c l} K_{V c 0} G_{C c 0} G_{\text {line }}^{\mathrm{ac} / \mathrm{dc}} G_{C d c}^{\mathrm{ac} / \mathrm{dc}}}{G_{L c 0}^{c l} K_{V c 0} G_{C c 0} G_{\text {line }}^{\mathrm{ac} / \mathrm{dc}} G_{C d c}^{\mathrm{ac} / \mathrm{dc}}+G_{\text {line }}^{\mathrm{ac} / \mathrm{dc}} G_{C d c}^{\mathrm{ac} / \mathrm{dc}}+} \\
G_{\text {line }}^{\mathrm{ac} / \mathrm{dc}} G_{C c 0}+G_{L c 0}^{c l} K_{V c 0} G_{C c 0}+1, \\
G_{\text {line }}^{\mathrm{ac} / \mathrm{dc}}=\frac{1}{r_{\text {line }}^{\mathrm{ac} / \mathrm{dc}}+s L_{\text {line }}^{\mathrm{ac} / \mathrm{dc}}}, G_{C d c}^{\mathrm{ac} / \mathrm{dc}}=\frac{1+s r_{c d c}^{\mathrm{ac} / \mathrm{dc}} C_{d c}^{\mathrm{ac} / \mathrm{dc}}}{s C_{d c}^{\mathrm{ac} / \mathrm{dc}}} .
\end{array}
$$

\section{REFERENCES}

[1] A. Mohd, E. Ortjohann, A. Schmelter, N. Hamsic, and D. Morton, "Challenges in integrating distributed Energy storage systems into future smart grid," in Proc. 2008 IEEE Int. Symp. Industrial Electronics, Jun. 2008, pp. 1627-1632.

[2] H. Chen, T. N. Cong, W. Yang, C. Tan, Y. Li, and Y. Ding, "Progress in electrical energy storage system: A critical review," Progr. Nat. Sci., vol. 19, no. 3, pp. 291-312, Mar. 2009.

[3] J. J. Justo, F. Mwasilu, J. Lee, and J.-W. Jung, "AC-microgrids versus DC-microgrids with distributed energy resources: A review," Renew. Sustain. Energy Rev., vol. 24, pp. 387-405, Aug. 2013. 
[4] D. Boroyevich, I. Cvetkovic, D. Dong, R. Burgos, F. Wang, and F. Lee, "Future electronic power distribution systems a contemplative view," in Proc. 2010 12th Int. Conf. Optimization of Electrical and Electronic Equipment, May 2010, pp. 1369-1380.

[5] H. Ikebe, "Power Systems for Telecommunications in the IT Age," in Proc. 25th Int. Telecommunications Energy Conf., 2003 (INTELEC '03), 2003, pp. 1-8.

[6] G. Wang, M. Ciobotaru, and V. G. Agelidis, "Power smoothing of large solar PV plant using hybrid energy storage," IEEE Trans. Sustain. Energy, vol. 5, no. 3, pp. 834-842, Jul. 2014.

[7] H. Kakigano, Y. Miura, and T. Ise, "Low-voltage bipolar-type DC microgrid for super high quality distribution," IEEE Trans. Power Electron., vol. 25, no. 12, pp. 3066-3075, Dec. 2010.

[8] D. J. Becker and B. Sonnenberg, "DC microgrids in buildings and data centers," in Proc. 2011 IEEE 33rd Int. Telecommunications Energy Conf. (INTELEC), Oct. 2011, pp. 1-7.

[9] A. M. Gee, F. V. P. Robinson, and R. W. Dunn, "Analysis of battery lifetime extension in a small-scale wind-energy system using supercapacitors," IEEE Trans. Energy Convers., vol. 28, no. 1, pp. 24-33, Mar. 2013.

[10] B. Hredzak, V. G. Agelidis, and G. D. Demetriades, "A low complexity control system for a hybrid DC power source based on ultracapacitorlead-acid battery configuration," IEEE Trans. Power Electron., vol. 29, no. 6, pp. 2882-2891, Jun. 2014.

[11] S. Vazquez, S. M. Lukic, E. Galvan, L. G. Franquelo, and J. M. Carrasco, "Energy storage systems for transport and grid applications," IEEE Trans. Ind. Electron., vol. 57, no. 12, pp. 3881-3895, Dec. 2010

[12] J. Vetter, P. Novák, M. Wagner, C. Veit, K.-C. Möller, J. Besenhard, M. Winter, M. Wohlfahrt-Mehrens, C. Vogler, and A. Hammouche, "Ageing mechanisms in lithium-ion batteries," J. Power Sources, vol. 147 , no. $1-2$, pp. 269-281, Sep. 2005.

[13] P. Thounthong, S. Rael, and B. Davat, "Analysis of supercapacitor as second source based on fuel cell power generation," IEEE Trans. Energy Convers., vol. 24, no. 1, pp. 247-255, Mar. 2009.

[14] S. Lemofouet and A. Rufer, "A hybrid energy storage system based on compressed air and supercapacitors with maximum efficiency point tracking (MEPT)," IEEE Trans. Ind. Electron., vol. 53, no. 4, pp. 1105-1115, Jun. 2006.

[15] S. Govindan, A. Sivasubramaniam, and B. Urgaonkar, "Benefits and limitations of tapping into stored energy for datacenters," in Proc. 38th Annu. Int. Symp. Computer Architecture-ISCA '11, New York, NY, USA, 2011, p. 341.

[16] J. M. Guerrero, P. C. Loh, T.-L. Lee, and M. Chandorkar, "Advanced control architectures for intelligent microgrids-part II: Power quality, energy storage, AC/DC microgrids," IEEE Trans. Ind. Electron., vol. 60, no. 4, pp. 1263-1270, Apr. 2013.

[17] D. Wang, C. Ren, A. Sivasubramaniam, B. Urgaonkar, and H. Fathy, "Energy storage in datacenters: What, where and how much?," $A C M$ SIGMETRICS Perform. Eval. Rev., vol. 40, no. 1, p. 187, Jun. 2012.

[18] T. Morstyn, B. Hredzak, and V. G. Agelidis, "Distributed cooperative control of microgrid storage," IEEE Trans. Power Syst., vol. 30, no. 5, pp. 2780-2789, Sep. 2015.

[19] A. Etxeberria, I. Vechiu, H. Camblong, J. Vinassa, and H. Camblong, "Hybrid energy storage systems for renewable energy sources integration in microgrids: A review," in Proc. 2010 Conf. IPEC, Oct. 2010, pp. 532-537.

[20] N. L. Diaz, T. Dragicevic, J. C. Vasquez, and J. M. Guerrero, "Intelligent distributed generation and storage units for DC microgrids-a new concept on cooperative control without communications beyond droop control," IEEE Trans. Smart Grid, vol. 5, no. 5, pp. 2476-2485, Sep. 2014.

[21] C. Li, T. Dragicevic, N. L. D. Aldana, J. C. Vasquez, and J. M. Guerrero, "Voltage scheduling droop control for state-of-charge balance of distributed energy storage in DC microgrids," in Proc. 2014 IEEE Int. Energy Conf. (ENERGYCON), 2014.

[22] X. Lu, K. Sun, J. Guerrero, and J. L. Vasquez, "SoC-based droop method for distributed energy storage in DC microgrid applications," in Proc. 2012 IEEE Int. Symp. Industrial Electronics (ISIE), 2012, pp. $1640-1645$.

[23] T. Dragicevic, J. M. Guerrero, J. C. Vasquez, and D. Skrlec, "Supervisory control of an adaptive-droop regulated DC microgrid with battery management capability," IEEE Trans. Power Electron., vol. 29, no. 2, pp. 695-706, Feb. 2014.

[24] H. Babazadeh, B. Asghari, and R. Sharma, "A new control scheme in a multi-battery management system for expanding microgrids," in Proc. ISGT 2014, Feb. 2014, vol. 95014, pp. 1-5.
[25] D. J. Hill, T. Liu, and G. Verbic, "Smart grids as distributed learning control," in Proc. 2012 IEEE Power and Energy Soc. General Meeting, Jul. 2012, pp. 1-8.

[26] F. L. Lewis, H. Zhang, K. Hengster-Movric, and A. Das, Cooperative Control of Multi-Agent Systems, ser. Communications and Control Engineering. London, U.K.: Springer London, 2014.

[27] C. Langbort, R. Chandra, and R. D'Andrea, "Distributed control design for systems interconnected over an arbitrary graph," IEEE Trans. Automa. Control, vol. 49, no. 9, pp. 1502-1519, Sep. 2004.

[28] S. D. J. McArthur, E. M. Davidson, V. M. Catterson, A. L. Dimeas, N. D. Hatziargyriou, F. Ponci, and T. Funabashi, "Multi-agent systems for power engineering applications-part I: Concepts, approaches, technical challenges," IEEE Trans. Power Systems, vol. 22, no. 4, pp. 1743-1752, Nov. 2007.

[29] H. G. Tanner, A. Jadbabaie, and G. J. Pappas, "Flocking in fixed and switching networks," IEEE Trans. Autom. Control, vol. 52, no. 5, pp. 863-868, May 2007.

[30] A. Jadbabaie and A. Morse, "Coordination of groups of mobile autonomous agents using nearest neighbor rules," IEEE Trans. Autom. Control, vol. 48, no. 6, pp. 988-1001, Jun. 2003.

[31] R. Olfati-Saber, "Flocking for multi-agent dynamic systems: Algorithms and theory," IEEE Trans. Autom. Control, vol. 51, no. 3, pp. 401-420, Mar. 2006.

[32] F. L. Lewis and A. Das, "Optimal design for synchronization of cooperative systems: State feedback, observer and output feedback," IEEE Trans. Autom. Control, vol. 56, no. 8, pp. 1948-1952, Aug. 2011.

[33] P. Wieland, R. Sepulchre, and F. Allgöwer, "An internal model principle is necessary and sufficient for linear output synchronization," $\mathrm{Au}$ tomatica, vol. 47, no. 5, pp. 1068-1074, May 2011.

[34] J. Lunze, "An internal-model principle for the synchronisation of autonomous agents with individual dynamics," in Proc. IEEE Conf. Decision and Control and Eur. Control Conf., Dec. 2011, no. 1, pp. 2106-2111.

[35] Q. Shafiee, T. Dragicevic, J. C. Vasquez, and J. M. Guerrero, "Hierarchical control for multiple DC-microgrids clusters," IEEE Trans. Energy Convers., vol. 29, no. 4, pp. 922-933, Dec. 2014.

[36] V. Nasirian, S. Moayedi, A. Davoudi, and F. Lewis, "Distributed cooperative control of DC microgrids," IEEE Trans. Power Electron., vol. 30, no. 4, pp. 2288-2303, Apr. 2015

[37] T. Morstyn, B. Hredzak, V. G. Agelidis, and G. Demetriades, "Cooperative control of DC microgrid storage for energy balancing and equal power sharing," in Proc. 2014 Australasian Universities Power Engineering Conf. (AUPEC), Sep. 2014, no. Oct., pp. 1-6.

[38] T. Morstyn, B. Hredzak, G. D. Demetriades, and V. G. Agelidis, "Unified distributed control for DC microgrid operating modes," IEEE Trans. Power Syst., to be published.

[39] T. Dragicevic, J. M. Guerrero, and J. C. Vasquez, "A distributed control strategy for coordination of an autonomous LVDC microgrid based on power-line signaling," IEEE Trans. Ind. Electron., vol. 61, no. 7, pp. 3313-3326, Jul. 2014.

[40] P. Sanchis, A. Ursaea, E. Gubia, and L. Marroyo, "Boost DC-AC inverter: A new control strategy," IEEE Trans. Power Electron., vol. 20, no. 2, pp. 343-353, Mar. 2005.

[41] S. Zhang, K. Xu, and T. Jow, "Study of the charging process of a LiCoO2-based Li-ion battery," J. Power Sources, vol. 160, no. 2, pp. 1349-1354, Oct. 2006.

[42] W. Huang and J. Abu Qahouq, "Energy sharing control scheme for state-of-charge balancing of distributed battery energy storage system," IEEE Trans. Ind. Electron., vol. 62, no. 5, pp. 2764-2776, May 2015.

[43] Z. Yang, C. Shen, L. Zhang, M. Crow, and S. Atcitty, "Integration of a StatCom and battery energy storage," IEEE Trans. Power Syst., vol. 16, no. 2, pp. 254-260, May 2001

[44] L. Shi and M. L. Crow, "Comparison of ultracapacitor electric circuit models," in Proc. 2008 IEEE Power and Energy Soc. General Meeting-Conversion and Delivery of Electrical Energy in the 21st Century, Jul. 2008, pp. 1-6.

[45] G. L. Plett, "Extended Kalman filtering for battery management systems of LiPB-based HEV battery packs," J. Power Sources, vol. 134, no. 2, pp. 262-276, Aug. 2004.

[46] P. Wieland and F. Allgöwer, "An internal model principle for consensus in heterogeneous linear multi-agent systems," Estim. Control Netw. Syst., vol. 1, no. 1, pp. 7-12, Sep. 2009.

[47] Y. Gu, X. Xiang, W. Li, and X. He, "Mode-adaptive decentralized control for renewable DC microgrid with enhanced reliability and flexibility," IEEE Trans. Power Electron., vol. 29, no. 9, pp. 5072-5080, Sep. 2014 
[48] T. Tanaka, K. Hirose, D. Marquet, B. Sonnenberg, and M. Szpek, "Analysis of wiring design for 380-VDC power distribution system at telecommunication sites," in Proc. Intelec 2012, Sep. 2012, pp. 1-5.

[49] D. Wang, C. Ren, S. Govindan, A. Sivasubramaniam, B. Urgaonkar, A. Kansal, and K. Vaid, "ACE: Abstracting, characterizing and exploiting datacenter power demands," in Proc. 2013 IEEE Int. Symp. Workload Characterization (IISWC), Sep. 2013, pp. 44-55.

[50] X. Fan, W.-D. Weber, and L. A. Barroso, "Power provisioning for a warehouse-sized computer," in Proc. 34th Annu. Int. Symp. Computer Architecture—ISCA '07, New York, NY, USA, 2007, p. 13.

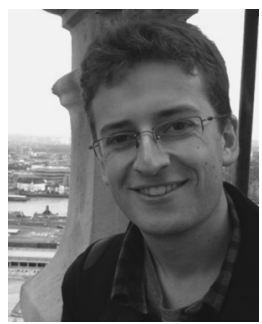

Thomas Morstyn (S'13) received the B.E. (Hon.) degree in electrical engineering from the University of Melbourne, Australia, in 2012. He is currently working towards the Ph.D. degree at the Australian Energy Research Institute, The University of New South Wales, Sydney, NSW, Australia.

$\mathrm{He}$ worked as an electrical engineer in the Rio Tinto Technology and Innovation group for two years. His current research interests include control systems for the integration of distributed renewable generation and storage into power networks.

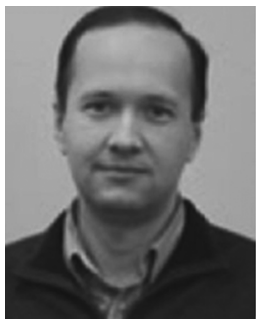

Branislav Hredzak (M'98-SM'13) received the B.Sc./M.Sc. degree from the Technical University of Kosice, Slovak Republic, in 1993, and the Ph.D. degree from Napier University of Edinburgh, U.K., in 1997, all in electrical engineering.

He was a Lecturer and a Senior Researcher in Singapore from 1997 to 2007 . He is currently a Senior Lecturer in the School of Electrical Engineering and Telecommunications, The University of New South Wales, Sydney, NSW, Australia. His current research interests include hybrid storage technologies and advanced control systems for power electronics and storage systems.

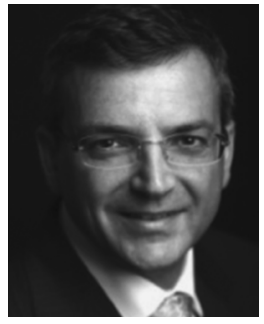

Vassilios G. Agelidis (S'89-M'91-SM'00) was born in Serres, Greece. He received the B.Eng. degree in electrical engineering from the Democritus University of Thrace, Thrace, Greece, in 1988, the M.S. degree in applied science from Concordia University, Montreal, QC, Canada, in 1992, and the Ph.D. degree in electrical engineering from the Curtin University, Perth, WA, Australia, in 1997.

From 1993 to 1999, he was with the School of Electrical and Computer Engineering, Curtin University. In 2000, he joined the University of Glasgow, Glasgow, U.K., as a Research Manager for the Glasgow-Strathclyde Centre for Economic Renewable Power Delivery. In addition, he has authored/co-authored several journal and conference papers as well as Power Electronic Control in Electrical Systems in 2002. From January 2005 to December 2006, he was the inaugural Chair of Power Engineering in the School of Electrical, Energy, and Process Engineering, Murdoch University, Perth. From December 2006 to June 2010, he was the Energy Australia Chair of Power Engineering at the University of Sydney. He is currently the Director of the Australian Energy Research Institute, The University of New South Wales, Sydney, NSW, Australia.

Dr. Agelidis received the Advanced Research Fellowship from the United Kingdoms Engineering and Physical Sciences Research Council in 2004 $\mathrm{He}$ was the Vice President Operations within the IEEE Power Electronics Society during 2006-2007. He was an Associate Editor of the IEEE POWER ELECTRONICS LETTERS from 2003 to 2005, and served as the Power Electronics Society (PELS) Chapter Development Committee Chair from 2003 to 2005. He was an AdCom Member of IEEE PELS for 2007-2009 and the Technical Chair of the 39th IEEE Annual Power Electronics Specialists Conference, Rhodes, Greece. 